\title{
How is radial arm maze behavior in rats related to locomotor search tactics?
}

\author{
CYNTHIA M. HOFFMAN, WILLIAM TIMBERLAKE, JOSEPH LEFFEL, and RORY GONT \\ Indiana University, Bloomington, Indiana
}

\begin{abstract}
Norway rats have been shown to depend on short-term spatial memory to find food on a radial arm maze (RAM), but what locomotor search tactics are involved in using this memory effectively? Four experiments distinguished tactics of distance minimizing, central-place search, trail following, thigmotactic search, and random search by using different configurations of a RAM placed flat on the floor of an arena. These search tactics make similar predictions on an elevated RAM but predict different outcomes on a floor RAM because the rats are free to approach the food from any direction. After initial trials dominated by exploration, rats traveled along arms to food, even when the resultant distance was up to three times the minimum distance. With no food present, rats also traveled along arms; with no arms up to present, they traveled along walls to food. It appears that both maze arms and arena walls engage mechanisms related to trail following in rats.
\end{abstract}

The arms of a typical radial arm maze (RAM) are elevated off the floor and project at equal angles from a central platform. At the beginning of a trial, each arm is baited with a small amount of food, and the rat is placed on the central platform and allowed to roam the maze until a set number of arm choices has been made or a fixed amount of time has passed. Because the maze is elevated, the rat must find food by choosing and traveling to the end of an arm and then retracing its steps to the center platform before choosing again. To collect all the food without wasted effort, the rat must visit each arm only once. Olton and Samuelson (1976) found that after minimal experience, rats chose nearly all novel (baited) arms in a trial without revisiting and without depending on a simple response rule, such as "always choose the arm to the left."

Most investigations of RAM behavior have focused on the importance of short-term spatial memory in allowing rats to avoid arms previously visited during the current trial (e.g., Beatty \& Shavalia, 1980; Olton, 1983; Suzuki, Augerinos, \& Black, 1980). Relatively little attention has been paid to the possible search tactics and underlying foraging strategy that provide the context for using spatial memory. Most investigators agree that the global strategic basis of foraging is some approximation to maximizing the benefit-to-cost ratio in finding food, but the local rules and tactics by which this global strategy is implemented must be worked out in each case (Stephens \& Krebs, 1986). Olton (1982) suggested that rats on a RAM used a win-shift rule to avoid repeating an already-chosen arm. Combined with spatial memory, this rule helps ac-

This study was supported in part by National Science Foundation Grants IBN 9408366, IBN-9817175, and BIR-9413220. C.M.H. was supported by National Research Service Award IF32MH10662. Thanks to John Roche for comments. Correspondence should be addressed to W. Timberlake, Department of Psychology, Indiana University, Bloomington, IN 47405 (e-mail: timberla@indiana.edu) count for the rat's effective search of the RAM, but winshift does not uniquely specify a locomotor search tactic. At least four tactics for implementing a win-shift rule are potentially present: (1) distance minimizing, (2) centralplace search, (3) trail following, and (4) random search (meandering).

A distance-minimizing tactic minimizes the distance traveled between potential food sources to maximize net rate of energy gain (Krebs \& McCleery, 1984; Stephens \& Krebs, 1986). Other things equal, a distance-minimizing rat should travel the most direct route between food locations. Alternatively, a central-place search tactic consists of venturing out to potential food sources and returning to a central location between forays (e.g., Stephens \& Krebs, 1986), a pattern that decreases continuous exposure to predation (Lima \& Dill, 1990). In the field, the central place is usually a permanent burrow or temporary shelter. In the laboratory, the central place has been assumed to be a point of intersecting pathways on a maze (Phelps \& Roberts, 1989) or the location at which a subject is first placed in an apparatus (Barnett, 1975). In the case of a RAM, the central platform is usually presumed to be the central place. A trail-following tactic consists of following specific routes to potential resources. Trail following is prevalent in colonies of Norway rats (Rattus norvegicus). Colony members create extensive trails above ground (Calhoun, 1962) and follow them almost exclusively (Telle, 1966). Trails usually lead to food sources or harborage sites (Calhoun, 1962; Telle, 1966). In the case of a RAM, the maze arms may serve as trails leading to food. Finally, in a random search tactic, rats follow an unpredictable route to discover food locations.

On a typical elevated RAM, these locomotor tactics (distance minimizing, central-place search, trail following, and random search), in conjunction with spatial memory and a rule such as win-shift, all predict the same outcome. After returning to the central location following an 
initial choice, rats should continue to choose novel arms until all arms are chosen. To distinguish the potential contributions of these different tactics to RAM foraging, we removed the requirement of remaining on the maze arms by placing the RAM flat on the floor of a large arena. Because the rats were free to approach the food cups from any direction either on or off the arms, the different tactics now predicted different locomotor patterns. Placing the RAM on the floor also introduced a fifth potential tacticsearching for food by traveling along the walls of the arena (thigmotactic search) - and likely increased the possibility of a sixth outcome, ineffective search.

In four experiments, we manipulated the number and location of the maze arms comprising the floor RAM to distinguish among the above tactics. Experiment.1 showed that traveling on or beside the maze arms took precedence over distance minimizing, central-place search, random search, and thigmotactic search. Experiment 2 showed that search based on arm travel occurred even in the absence of any food. Experiment 3 showed that rats traveled along walls to food when there were no arms, and they demonstrated distance minimizing if the available arms traced only a direct route between food cups. Experiment 4 further supported the dominance of trail following by showing that even when maze arms led all the way around the arena walls to get to food, rats still traveled along them.

\section{EXPERIMENT 1}

The purpose of Experiment 1 was to establish the characteristics of floor-maze foraging behavior and to examine contributions of the search tactics outlined above. In the standard-arm condition, rats were placed once a day in the center of a baited six-arm RAM placed flat on the floor of a large arena (the maze arms reached approximately halfway from the center platform to the arena walls). The sizes of the central platform and the maze arms were typical of elevated RAMs (e.g., Olton \& Samuelson, 1976).

The rats were able to display up to five locomotor tactics in effectively searching for food. They could minimize their foraging distance by traveling from the center along an arm to an initial cup and, from there, in a direct circular route from one food cup to the next (see Figure 1a). Alternatively, the rats could show a central-place search tactic by traveling along maze arms from the center to a cup and return (see Figure lb). The same pattern of traveling would be expected if the rats showed a trailfollowing tactic. The rats also could follow a random search route to food cups, meandering around the arena (Figure Ic), or display a thigomotactic locomotor pattern, traveling along the walls of the arena between food cups (Figure 1d). Finally, the rats could fail to effectively locate the cups. Note that the distance-minimizing tactic has a marked potential advantage relative to the others in the length of the route necessary to obtain the food. Given six equally spaced arms, a rat showing a pure central- place or trail-following tactic must travel twice as far to pick up the food as a rat showing a distance-minimizing tactic. A rat showing random locomotion or thigmotactic search might locomote even farther.

For the circle-and-spoke condition, maze arms were added to the floor RAM so that the food cups were connected directly to each other as well as to the central platform (thus, the circle-and-spoke designation). This manipulation allowed rats to show three tactics without leaving the maze arms: distance minimizing, central-place search, and trail following. Distance minimizing could be achieved by traversing an arm to the first cup and then traveling along connecting arms in a circular route between food cups. Central-place search could be shown by a route consistently leaving from and returning to the central platform. Finally, trail following could be reflected in any continued sampling of both circle-and-spoke arms. Of course, the rats were also free to show tactics of random search on and off the maze arms, thigmotactic search, and ineffective search.

Our basic measures of performance were of two sorts: those focused on effective location of all the food cups (number of novel cups chosen out of a maximum of six visits, and time to end the trial); and those directed at the pattern of locomotion (including modal locomotor route, adjacent cup choice, number of arcs between food cups, and the proportion of distance traveled along the maze arms and the arena walls and in the open). Finally, because there are data that indicate that rats can follow odor trails to food (e.g., Galef \& Buckley, 1996; Morrison \& Ludvigson, 1970), we cleaned the maze and arena floor between subgroups of 4 rats, and we compared the behavior of rats tèsted after cleaning with those tested following 2 or more previous rats.

\section{Method}

\section{Subjects}

Sixteen (90-120-day-old) female Sprague-Dawley albino rats (Rattus norvegicus) bred at the Indiana University colony served as maze-naive subjects. The rats were housed separately in wire cages and kept under a 12:12-h light:dark schedule, with lights on at 7 a.m. Prior to the experiment, rats weighing less than $240 \mathrm{~g}$ were reduced to $90 \%$ of their ad-lib weight, and rats weighing over $240 \mathrm{~g}$ were reduced to $85 \%$ of their ad-lib weight. The rats were handled for approximately $5 \mathrm{~min}$ each day for 2 days prior to the experiment. The rats were given ten to fifteen $45-\mathrm{mg}$ Bio-Serv pellets in their home cage for 2 days prior to the experiment to acquaint them with the food reinforcer available on the maze. To keep their weights stable, all rats were given a daily food supplement of Purina Chow $0.5 \mathrm{~h}$ after the last rat's daily session. The rats had access to water at all times in their home cage. Testing was conducted between 2 and 7 p.m., 6 days a week.

\section{Apparatus}

The six-arm radial maze was constructed of 1.9-cm-thick wood and $0.5-\mathrm{cm}$-thick Masonite (a hard fiberboard). The entire apparatus was painted gray. The six wooden arms radiated from a hexagonal center, with a $60^{\circ}$ angle between adjacent arms. The center measured $45 \mathrm{~cm}$ from point to opposite point of the hexagon. Each arm was $13 \mathrm{~cm}$ wide and $70 \mathrm{~cm}$ long. A $3.8-\mathrm{cm}$-high $0.5-\mathrm{cm}$-thick Masonite border was attached to both sides and the end of each maze arm. The height of the border when the rat was standing on 

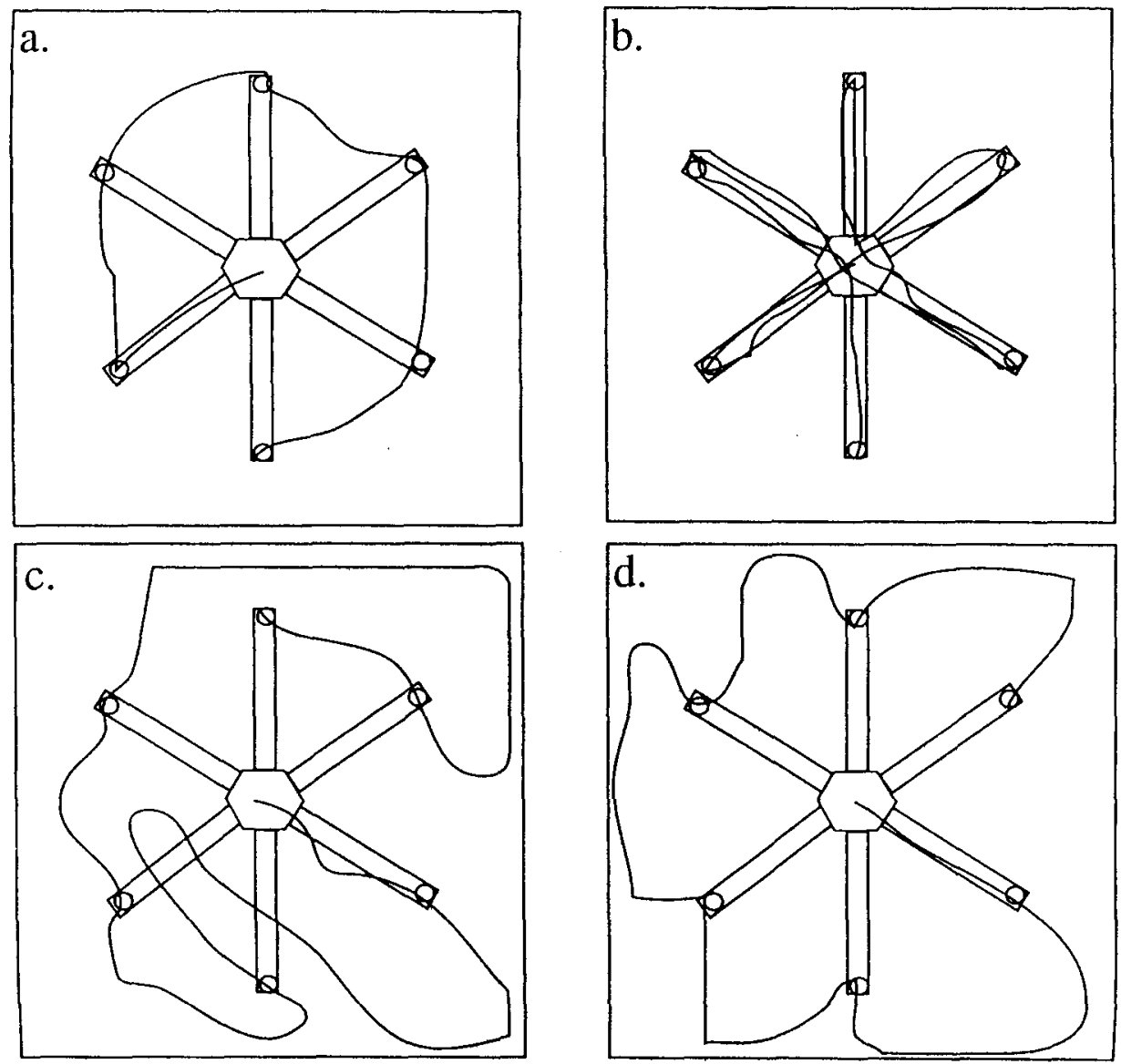

Figure 1. A representation of the routes satisfying five possible rat foraging tactics on a radial maze on the floor: (a) distance-minimizing search, (b) either central-place search or efficient trail following (arm travel), (c) random (meandering) search, and (d) thigmotactic search (wall travel).

the $1.9-\mathrm{cm}$-thick maze arm was only $1.9 \mathrm{~cm}$ high, so that the rats readily stepped off and on the maze. Maze arms that were placed between cups in the circle-and-spoke condition did not have a border at either end of the arm.

The center of the maze was bordered by $3.8-\mathrm{cm}$-high pieces of the Masonite where the arms did not contact the center. A top made of clear Plexiglas, with alternating 1.2-cm strips of black construction paper, was mounted $15 \mathrm{~cm}$ above the center to provide a semicovered central area for the foraging rat. The apparatus was placed on the floor of the experimental room. A ceramic food cup, $7.5 \mathrm{~cm}$ in diameter and $5 \mathrm{~cm}$ tall, was placed on the floor at the end of each radial arm. The rats could easily take food from the cup while standing on the arm or on the floor next to the arm.

The rats were transported to and from a staging area outside the experimental room in a 4-rat carrier, each rat in an individual $10 \times$ $20 \mathrm{~cm}$ compartment. One rat at a time was removed from the carrier and taken into the experimental room. The experimental room was dimly lit with a single $60-\mathrm{W}$ bare bulb hanging from the ceiling in the center of the room directly above the center of the maze. The light was sufficient for the experimenter to observe the rat and record data. The experimental room was quiet and measured $3.2 \times 2.9 \mathrm{~m}$. The floor of the room was divided into $45.7-\mathrm{cm}$ squares by masking tape. The experimenter sat in a chair in one corner of the room.

\section{Procedure}

The rats were divided into two groups: 8 rats in the floor RAM group, and 8 rats in the circle-and-spoke group. The groups were run successively (rather than intermixed) to minimize the possibility that odor, visual, or auditory cues from animals in one condition could affect the behavior of the rats in the other conditions. The same experimenter ran all rats one trial per day at approximately the same time. One $45-\mathrm{mg}$ Bio-Serv pellet was placed in each cup prior to the beginning of a trial. A cup choice was scored when the rat's nose entered the cup.

At the beginning of each trial, the rat was placed in the center of the maze oriented away from the experimenter. During the trial, the experimenter traced the travel pattern that the rat followed on and off of the maze on a data sheet. The experimenter also recorded the cups visited, the time elapsed when the rat visited the sixth cup. and/or the time elapsed at the end of the trial. A trial ended when the rat had visited each of the six different cups and 1 additional minute had elapsed, or when the rat had made eight total cup visits, or when $10 \mathrm{~min}$ had elapsed. At the end of the trial, the rat was gently corralled into a cardboard box, picked up by the experimenter, and returned to the carrier.

The rats were tested for 12 trials in fixed subgroups of 4 ( $A$ and $B$ ) or 2 (C) rats. The order in which the subgroups were tested al- 
ternated between an $\mathrm{ABC}, \mathrm{BCA}$, and $\mathrm{CAB}$ sequence on successive trials. To decrease the likelihood that the rats' behavior would be influenced by odor cues left on the maze and on the floor of the room, the experimenter cleaned up any feces and urine deposited during a trial before the next rat was tested. For each group of rats, the arena and maze were thoroughly wiped down with Roccal-D (an institutional disinfectant and deodorant detergent).

\section{Method of Analysis}

To assess how effectively the rats located the available food each trial, we counted the number of different cups visited out of a maximum of six visits and compared this with the performance of other groups and with chance. The average novel cups visited tended to be low during the first few trials because the average rat did not visit a total of six cups before the trial timed out. However, during the last half of the trials, the rats rarely failed to visit six cups.

The number of novel arms that a rat should visit on an elevated six-arm maze on the basis of chance (assuming the rat did not remember and avoid already-visited cups and did not use a response algorithm) is 3.99. Chance was calculated with the following formula: $N-N[(N-1) / N]^{N}$, where $N$ is the total number of cups. This is probably too high an estimate for chance on a floor maze because the rat is not required to return to the center platform before making its next choice. Thus, the choices available to the rat immediately after choosing a particular cup most likely are weighted by the different distances of the food cups and so are effectively less than six equally likely choices. We used the present estimate of chance because it provided a common yardstick of performance across all the experiments.

The rats could perform well in this task by always choosing the next cup. We used two measures of this possibility: the proportion of successive visits to adjacent cups (dividing the number of successive cup visits by the total number of cup visits on each trial); and the number of arcs (instances in which the rat traveled directly from one cup to the next, without traveling along an arm or the wall or meandering about). A perfect distance minimizer should generate 5 arcs by traveling from the center out to a food cup and then in a circle visiting each of the other food cups in succession.

To describe how the rats distributed their movement in the room, we categorized movement as arm travel, open travel, and wall travel. Arm travel included locomotion on or parallel to the arm (within $5 \mathrm{~cm}$ of the edge of the arm) for a distance of more than $15 \mathrm{~cm}$. Arm travel also included travel across the center of the maze if the rat's subsequent travel continued along an arm. Wall travel included travel parallel to and within $30 \mathrm{~cm}$ of the wall. Locomotion that fit in neither the arm-travel category nor the wall-travel category was included in the category of open travel.

We measured the distance of arm travel, wall travel, and open travel by tracing with a pen mouse each rat's daily locomotion pattern as recorded by the experimenter on a data sheet. The software program Mouse Odometer 1.0 reported the distance moved in centimeters, which was multiplied by a scaling factor to obtain the actual meters traveled. The arm-travel, open-travel, and wall-travel portions of each trial's travel were traced separately. The experimenter traced each portion three times, and the mean of these three tracings was taken as the absolute distance of arm travel, open travel, or wall travel for that trial. The absolute distance traveled was totaled, and the proportions of arm travel, open travel, and wall travel were calculated for each trial for each rat and averaged by trial blocks.

Dependent variables were analyzed using mixed-design analyses of variance (ANOVAs). One-tailed $t$ tests were used to compare the choice of novel cups with that expected by chance and to compare the travel route of rats with that expected of an optimal forager. Data were combined into two-trial blocks before presentation and analysis. Transformations were applied as appropriate to reduce or remove correlations between group means and variances. We used an alpha level of .05 for reporting significant differences. Finally, to determine whether odors left on the maze and floor by the rats that ran early in each subgroup had an effect on the foraging behavior of the rats tested later in each subgroup, we conducted ANOVAs on all dependent variables, comparing the early rats (the first 2 rats in each subgroup) with the late rats (the last 2 rats in each subgroup).

\section{Results}

We divided the analyses into measures concerned primarily with (1) effectiveness in locating the novel food cups (novel cups visited in a maximum of six visits and time to complete a trial) and (2) locomotion patterns shown in finding the food (proportion of successive adjacent cup visits, number of arcs, and proportion of distance traveled along arms and walls and in the open).

\section{Cup Visits}

Novel cup visits. According to Figure 2, the circleand-spoke group was remarkable at choosing novel cups (during a maximum of six cup visits), performing at a level greater than chance from the very first trial block through the last $[t(7)=8.04]$. The standard-arm group reached a similar level of above-chance choice, but only across the last three trial blocks $[t(7)=3.23]$. The different course of the two groups in choosing novel cups over trial blocks gave rise to three significant ANOVA effects: a groups effect in which the circle-and-spoke rats chose more novel cups $[F(1,14)=10.1]$; a trial blocks effect due primarily to the increase in novel choices by the standard-arm rats $[F(5,45)=15.2]$; and a trial blocks $\times$ groups interaction $[F(5,70)=8.33]$.

As an aside, it should not be puzzling that rats initially may choose novel cups below our estimate of chance. The simplest reason is that, during the first few trials, a rat may choose fewer than six cups and, thus, have little or no opportunity to exceed the chance level based on six choices. A more complex reason, mentioned in the Method section, is that our estimate of chance is high for a floor maze. It is based on the assumption that all food cups are equally distant from the choice point, a result that better characterizes elevated mazes where the rat must return to the central platform to choose the next cup. On a floor maze, rats are much more likely to choose when away from the center platform and, thus, at a point where the cups are not equally distant. Presuming that choice evaluations of food cups include their distance from the choice point, we should expect rats to more frequently choose nearby cups, thereby producing a lower level of choosing novel cups by chance. Because we could not easily estimate this lower level, it is most appropriate to treat the calculated chance level as a performance standard rather than as true chance.

Time. As Table la shows, the log time to visit a maximum of six food cups decreased significantly over trial 


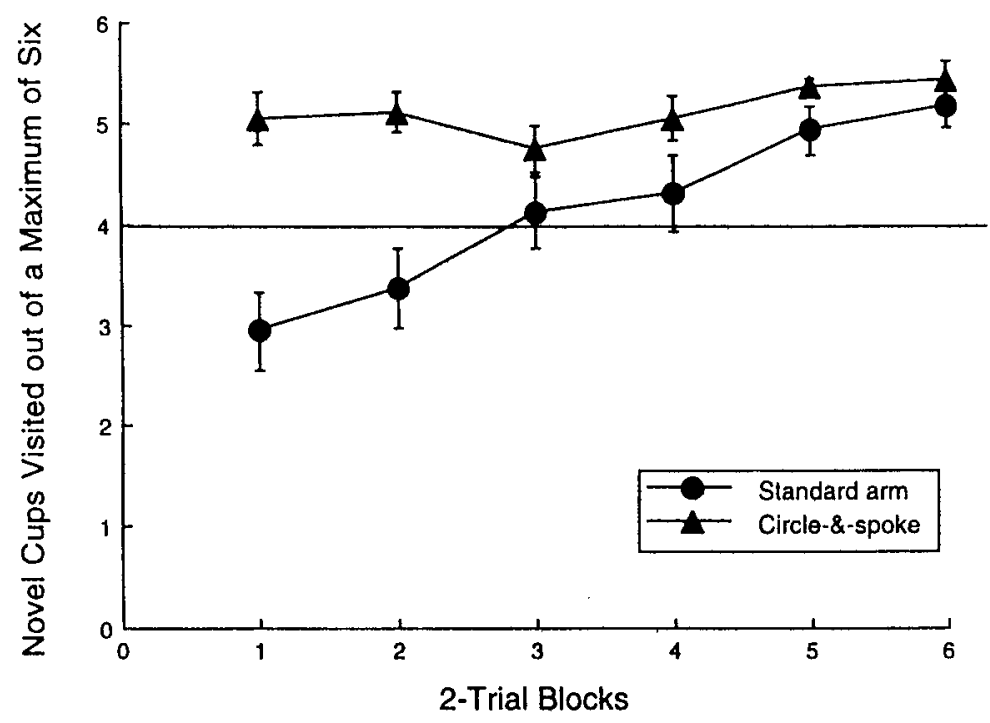

Figure 2. Mean number of novel cups visited in a maximum of six visits for the standard-arm floor RAM versus the circle-and-spoke floor RAM in Experiment 1. (The solid horizontal line shows the number of novel cup visits in six choices predicted by chance computed on the assumption that the animal makes six choices of equidistant food cups.)

blocks for the standard-arm and circle-and-spoke mazes $[F(5,70)=22.6]$, with the circle-and-spoke rats taking significantly less time $[F(1,14)=28.8]$.

\section{Locomotion Patterns}

The rats in both conditions traveled on the maze arms, beside the arms on the floor, in the open, and along the walls. Figure 3 shows a modal route for each condition over the last four trials. Modal routes were constructed by modifying the tracings of one or more typical trials to reflect the four-trial averages of (1) proportion of visits to successive adjacent arms, (2) number of arcs, (3) number of novel cup visits, and (4) proportion of travel along arms, along walls, and in the open. Even though Figure 3 is restricted to the data of the last four trials, it still shows that the rats were physically capable of following a pattern of locomotor behavior appropriate to any of the foraging tactics we consider. Nonetheless, it appears that the rats did not follow a minimum-distance route-collecting food from all the cups by moving from cup to cup in a circle around the maze - in any condition, nor did they search randomly or in a thigmotactic pattern.

Adjacent cup visits and number of arcs. Table $1 b$ reveals that the circle-and-spoke rats were much more likely to visit adjacent cups than were their standard-arm controls $[F(1,14)=26.3]$, although the latter group did contribute to a slight but significant improvement over trial blocks $[F(5,70)=2.92]$. Table $1 \mathrm{c}$ reveals that adjacent cup choice by the circle-and-spoke rats was due mostly to traveling directly (in arcs) between food cups. The mean number of arcs per trial was significantly greater for the circle-and-spoke maze than for the standard- arm maze $[F(1,14)=111]$, with a significant increase over trials $[F(5,70)=4.14]$. However, even during the last trial block, the average number of arcs by the circle-andspoke rats was still short of what would be expected of a perfect distance minimizer ( 3.5 arcs vs. 5 arcs) $[t(7)=$ 3.64].

Proportion of distance traveled. Although the rats could have distributed their log proportions of travel type (summed over trial blocks) randomly among arm travel, wall travel, and open travel, they did not $[F(2,28)=33.8]$ (see Figure 4). Summed over both travel type and trial block, there was no difference in log proportions between the standard-arm and circle-and-spoke groups. Such a group difference was unlikely because the proportions of travel types for each rat summed to 1 in both groups; however, since the log proportions are not quite so constrained, a difference is possible. There also was no overall trial-block effect, but there were group $\times$ trial block and group $\times$ trial block $\times$ travel type interactions $[F(5,70)=4.40$, and $F(10,140)=2.12$, respectively $]$.

The rats in the standard-arm condition traveled along the maze arms and the walls more than they traveled in the open $\left[F_{\mathrm{S}}(1,7)=15.4\right.$ and 6.42 , respectively] (Figure 4a). Over trial blocks, the proportions of arm travel and wall travel did not change, whereas the proportion of open travel increased $[F(5,45)=7.96]$.

The rats in the circle-and-spoke condition also traveled along maze arms and walls more than they traveled in the open $[F \mathrm{~S}(1,7)=202.0$ and 14.9 , respectively $]$ (Figure $4 \mathrm{~b}$ ). In addition, they traveled along maze arms more than along walls $[F(1,7)=45.4]$. Over trial blocks, arm travel, wall travel, and open travel did not change 
Table 1

Mean Performance Measures and Standard Errors Averaged by Two-Trial Blocks for Experiment 1

\begin{tabular}{|c|c|c|c|c|c|c|c|c|c|c|c|c|c|c|}
\hline \multirow[b]{2}{*}{ Maze } & \multicolumn{2}{|c|}{ Block 1} & \multicolumn{2}{|c|}{ Block 2} & \multicolumn{2}{|c|}{ Block 3} & \multicolumn{2}{|c|}{ Block 4} & \multicolumn{2}{|c|}{ Block 5} & \multicolumn{2}{|c|}{ Block 6} & \multicolumn{2}{|c|}{ Overall } \\
\hline & $M$ & $S E$ & $M$ & $S E$ & $M$ & $S E$ & $M$ & $S E$ & $M$ & $S E$ & $M$ & $S E$ & $M$ & $S E$ \\
\hline \multicolumn{15}{|c|}{ (a) Mean Time (in Seconds) to Complete a Trial } \\
\hline Standard arm & 387 & 48 & 267 & 64 & 194 & 60 & 140 & 43 & 127 & 51 & 103 & 28 & 203 & 45 \\
\hline Circle and spoke & 91 & 21 & 47 & 7 & 58 & 11 & 47 & 11 & 35 & 6 & 25 & 5 & 51 & 6 \\
\hline \multicolumn{15}{|c|}{ (b) Mean Proportion of Successive Visits to an Adjacent Cup } \\
\hline Standa & .31 & .06 & .28 & .06 & .38 & .05 & .39 & .06 & .43 & .07 & .50 & .07 & .38 & .04 \\
\hline Circle and spoke & .57 & .05 & .65 & .04 & .61 & .06 & .65 & .05 & .70 & .02 & .68 & .06 & .64 & .03 \\
\hline \multicolumn{15}{|c|}{ (c) Mean Number of Arcs } \\
\hline Stan & 0.13 & 0.08 & 0.13 & 0.08 & 0.06 & 0.06 & 0.31 & 0.1 & 0.50 & 0.38 & 0.43 & 0.24 & 0.26 & 0.14 \\
\hline Circle and spoke & 2.4 & 0.37 & 3.1 & 0.35 & 2.6 & 0.35 & 3.2 & 0.25 & 3.5 & 0.21 & 3.5 & 0.41 & 3.0 & 0.64 \\
\hline
\end{tabular}

$\left[F_{\mathrm{s}}(5,35)=1.57,1.13\right.$, and 1.53 , respectively $]$. Finally, the rats on the circle-and-spoke maze traveled in the open not quite significantly less than the standard-arm rats $[F(1,14)=4.95]$. The proportion of travel along arms and walls did not differ between the circle-andspoke rats and the RAM rats $[F \mathrm{~s}(1,14)=1.96$ and $<1$, respectively].

Effect of odor. Although the maze and floor of the room were cleaned between the testing of each subgroup of rats in order to remove odor cues that might accumulate, odor trails were still able to accumulate within subgroups. To determine whether odors left on the maze and floor by the rats that ran early in a subgroup (the first 2 rats) had an effect on the foraging behavior of the rats tested later in the group (the 3rd and 4th rats) we conducted ANOVAs on all dependent variables, comparing the scores of the early rats with those of the late rats.

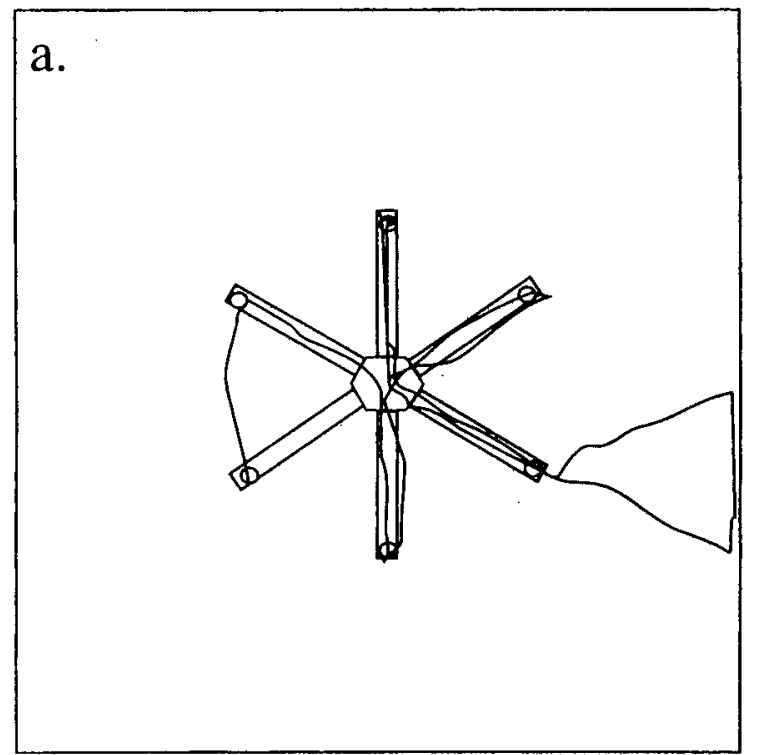

There were no significant differences between rats tested early and late in a subgroup on the baited RAM or on the circle-and-spoke maze in accuracy (the number of novel cups visited by the sixth cup visit or the proportion of successive visits to adjacent cups), time or travel pattern (proportion of travel along arms, along walls, or in the open, and number of arcs traveled per trial).

\section{Discussion}

After six trials, most rats in both the standard-arm condition and the circle-and-spoke condition came to effectively visit nearly all the novel food cups (with little repetition) at a level significantly above our estimate of chance. Both groups also completed their maximum of six cup visits more quickly over trials. At asymptote, the circle-and-spoke rats took less time to visit six food cups than did the standard-arm rats $(25 \mathrm{sec}$ vs. $103 \mathrm{sec})$.

Figure 3. Modal route of the rats in Experiment 1 on (a) the standard-arm floor RAM and (b) the circle-and-spoke floor RAM.

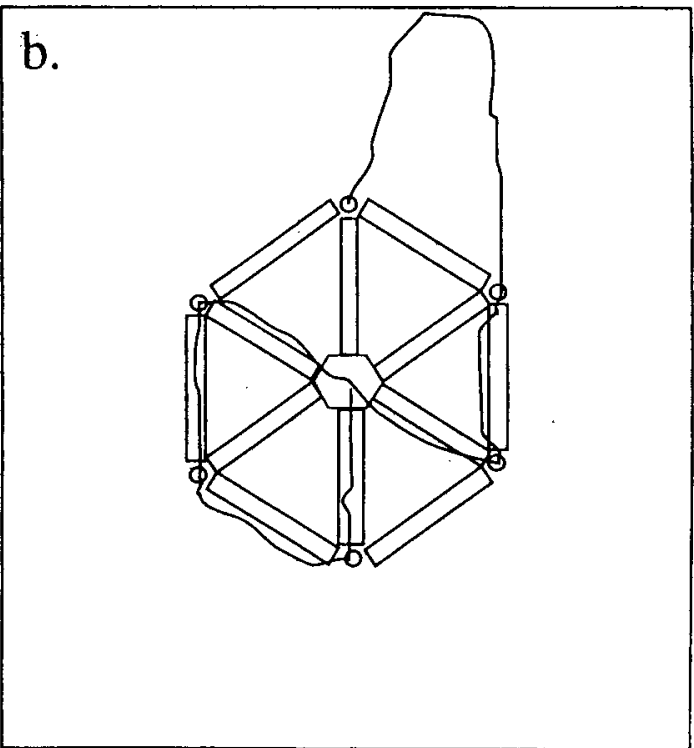


a

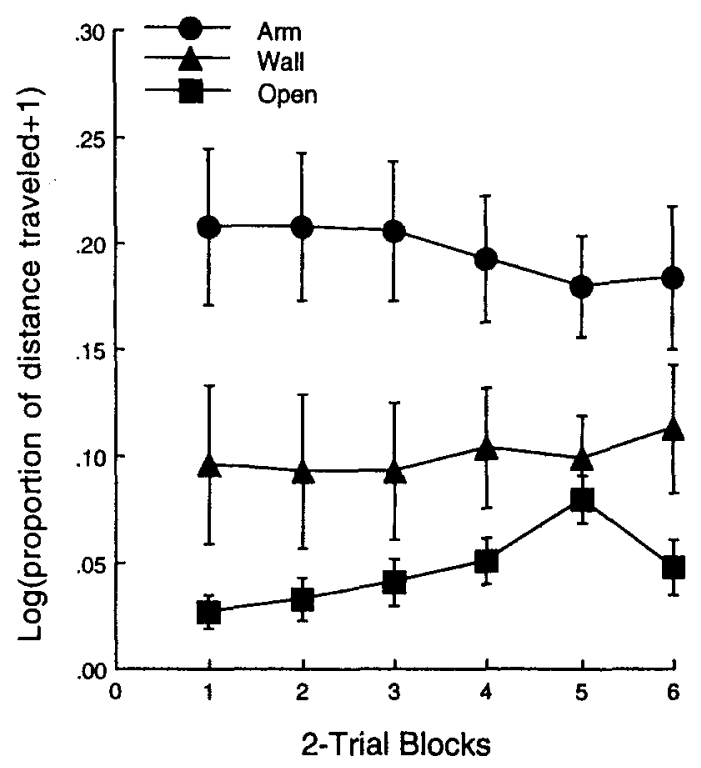

b

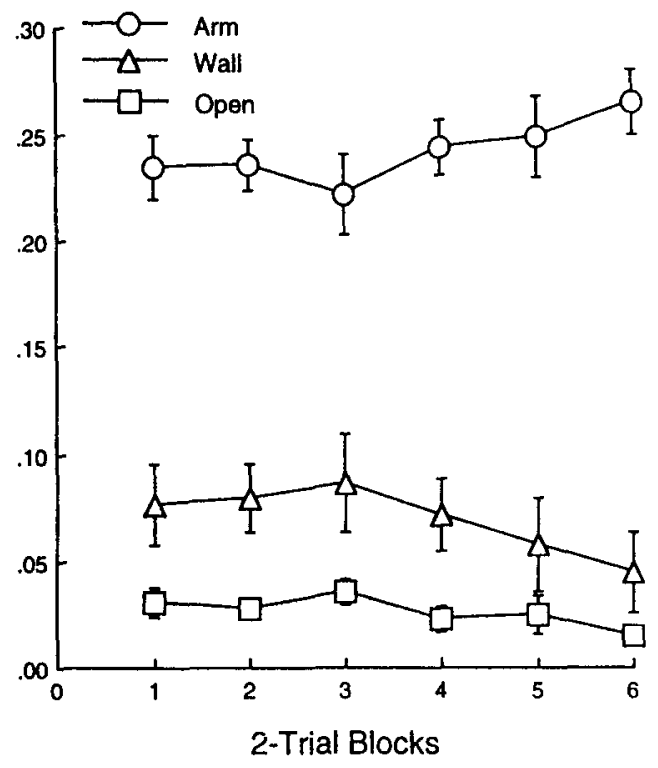

Figure 4. Mean log proportion of distance traveled along arms and walls and in the open by two-trial blocks for the rats in Experiment 1 on (a) the standard-arm floor RAM and (b) the circle-and-spoke RAM.

In both conditions, the rats traveled freely in the arena, on and off the maze arms, in the open, and along the walls. Clearly, they were physically able to locomote in patterns appropriate to any of the foraging tactics we considered. In spite of the many options, as trials increased, both groups moved toward predominant travel along maze arms to the food cups. At asymptote, the rats traveled on or alongside maze arms for over $65 \%$ of the total distance moved in the arena.

This pattern of locomotion on or beside arms is most compatible with the tactic of trail following. The data also are compatible with the idea that wall travel and arm travel are related, possibly as different expressions of trail following. Over trial blocks, there was a compensatory tradeoff between proportion of time spent in wall travel and arm travel in both conditions. The rats could have spent additional time in the open, but the proportion of distance traveled in the open did not differ across trials, whereas the proportion of arm travel increased markedly. The possibility that both maze arms and arena walls control trail following makes sense if we note that both arms and walls share the stimulus feature of a vertical edge that differs considerably in extent but can still be seen and contacted.

The tactic of pure distance minimizing received little support in our data. The rats rarely traveled from one food cup directly to the next (along an arc or a chord of the imaginary circle on which all the food cups were located) except in the circle-and-spoke configuration when arm segments connected the cups. Even in this instance, the behavior of the rats differed markedly from a strict distanceminimizing tactic. The rats in the standard-arm RAM condition showed a pattern of arm travel that could be in- terpreted as central-place search elicited by the configuration of the maze center and the cups spread around it. However, the same route was readily available to the rats on the circle-and-spoke maze, but they did not take it with high frequency. Instead, they followed a combination of arms, some radial from the center to the food cup and some directly between food cups.

Finally, given the importance of trail following in social colonies of rats and the importance of olfaction, there was surprisingly little evidence of a difference in behavior between rats running on a relatively clean versus a scented maze and arena.

\section{EXPERIMENT 2}

The results of Experiment 1 showed effective foraging, in that the rats in both groups came to choose nearly all the novel cups without repetition, but they did not show maximally efficient foraging in terms of distance traveled. The locomotor tactic most frequently shown appeared best described as trail following in the form of travel on top of and alongside maze arms. However, the evidence for trail following is not conclusive. The rats' behavior in the standard-arm condition did not distinguish trail following from central-place search, and their performance in the circle-and-spoke condition might be attributed to oscillating or compromising between the tactics of distance minimizing and central-place search. Furthermore, there is always the argument that the pattern of locomotor behavior can be attributed to the action of food in reinforcing specific approach responses.

The purpose of Experiment 2 was to test more directly whether arm travel represented a coherent trail-following 


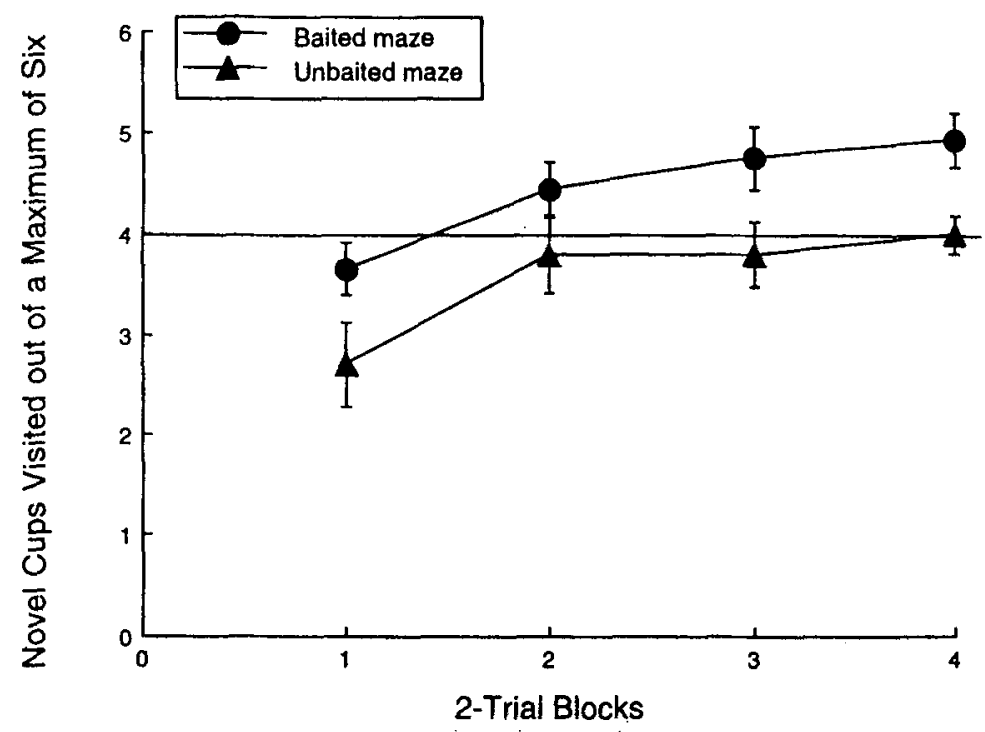

Figure 5. Mean number of novel cups visited in a maximum of six visits for the baited and unbaited standard-arm floor RAMs in Experiment 2. (The solid horizontal line shows the number of novel cup visits in six choices predicted by chance, per Figure 2.)

tactic by comparing rats run in the baited standard-arm condition of Experiment 1 with those run on an unbaited version of the same floor RAM. The baited standard-arm group was used to replicate the results of Experiment 1, whereas the unbaited group was used to test whether arm travel is a specific locomotor tactic that is expressed in dependent of finding food at the end of the arms.

It is worth noting that a finding of systematic and sustained arm travel on an unbaited floor maze would not be a complete surprise, given that Timberlake and White (1990) showed that a group of hungry rats on an unbaited elevated RAM searched the maze day after day very nearly as efficiently as a second group searched a baited maze. Bättig and Schlatter (1979) and Uster, Bättig, and Nägeli (1976) also showed efficient "patrolling" of unbaited maze-like environments by rats. Such behavior resembles the high levels of trail following that characterize colonies of Norway rats whether or not food is present (Calhoun, 1962; Telle, 1966). If the rats on our unbaited standardarm maze were to show arm travel even though they were not constrained to the arms and never encountered food on or off the arms, we would have some support for the hypothesis that arm travel is related to trail following and that trail following is based in part on mechanisms related to the characteristics of maze arms.

\section{Method}

\section{Subjects and Apparatus}

Twenty (90-120-day-old) female rats were obtained, housed, and maintained as in Experiment 1. The arena was slightly larger in area than the one in Experiment $1(3.6 \times 3.2 \mathrm{~m})$.

\section{Procedure}

The rats were divided into two groups: 10 rats in the baited standard-arm group and 10 in the unbaited standard-arm group. The rats were run on 8 trials instead of 12 , and, for the unbaited standard-arm group, no food was ever placed on the maze. Additionally, the baited and unbaited groups were run in sequence, rather than during the same time period, in order to prevent the presence of any food or activity-related cues from the baited group affecting the unbaited group. Other procedural details were the same as in Experiment 1 .

\section{Results}

We divided the analyses into measures concerned primarily with cup visits and measures concerned with patterns of locomotion.

\section{Cup Visits}

Novel cup visits. Figure 5 shows that the rats in the unbaited standard-arm maze visited fewer novel cups in a maximum of six visits than did the rats in their baited standard-arm maze control group $[F(1,18)=6.07]$. Both groups increased novel cups chosen over trial blocks $[F(3,54)=14.1]$, but, over the last two trial blocks, the baited rats chose novel cups above our estimate of chance $[t(9)=3.15]$, whereas the unbaited rats did not $[t(9)<1]$.

Time. Table 2a shows that the unbaited maze group took much more time to make a maximum of six cup visits than did the baited group $[F(1,18)=46.8]$, although both groups significantly decreased the time over trial blocks $[F(3,54)=62.3]$, and there was a significant interaction $[F(3,54)=10.4]$ due to the much slower rate of the drop in times by the unbaited group. 
Table 2

Mean Performance Measures and Standard Errors Averaged by Two-Trial Blocks for Experiment 2

\begin{tabular}{|c|c|c|c|c|c|c|c|c|c|c|}
\hline \multirow[b]{2}{*}{ Maze } & \multicolumn{2}{|c|}{ Block 1} & \multicolumn{2}{|c|}{ Block 2} & \multicolumn{2}{|c|}{ Block 3} & \multicolumn{2}{|c|}{ Block 4} & \multicolumn{2}{|c|}{ Overall } \\
\hline & $M$ & $S E$ & $M$ & $S E$ & $M$ & $S E$ & $M$ & $S E$ & $M$ & $S E$ \\
\hline \multicolumn{11}{|c|}{ (a) Mean Time (in Seconds) to Complete a Trial } \\
\hline Baited radial arm & 334 & 36 & 109 & 11 & 84 & 9 & 69 & 6 & 149 & 12 \\
\hline Unbaited radial arm & 544 & 21 & 351 & 59 & 385 & 57 & 304 & $\$ 4$ & 396 & 44 \\
\hline \multicolumn{11}{|c|}{ (b) Mean Proportion of Successive Visits to an Adjacent Cup } \\
\hline Baited radial arm & .28 & .05 & .19 & .05 & .31 & .05 & .33 & .05 & .28 & .02 \\
\hline Unbaited radial arm & .22 & .05 & .25 & .04 & .34 & .03 & .33 & .04 & .28 & .03 \\
\hline \multicolumn{11}{|c|}{ (c) Mean Number of Arcs } \\
\hline Baited radial arm & 0.3 & 0.11 & 0.1 & 0.06 & 0.4 & 0.21 & 0.5 & 0.22 & 0.31 & 0.11 \\
\hline Unbaited radial arm & 0.1 & 0.07 & 0.2 & 0.13 & 0.1 & 0.07 & 0.3 & 0.11 & 0.18 & 0.06 \\
\hline
\end{tabular}

\section{Locomotion Pattern}

The rats in both conditions traveled on the maze arms, beside the arms on the floor, in the open, and along the walls. Figure 6 shows a modal route for each condition constructed from the averages of the last four trials. As in Experiment 1, although the rats were physically capable of following a pattern of locomotor behavior appropriate to any of the foraging strategies, they did not follow a minimum-distance route-visiting all the cups by moving from cup to cup in a circle around the maze-in any condition, nor did they central-place forage (if one considers food an essential component of this tactic), nor search randomly or in a thigmotactic pattern.

Adjacent cup visits and number of arcs. Table $2 b$ shows that the unbaited standard-arm rats and their baited controls did not differ significantly from each other $[F(1,18)<1]$ or change over trials in their proportion of successive adjacent cup visits $[F(3,54)=2.73]$. Mean proportions of adjacent-cup visits were less than $40 \%$. Table $2 \mathrm{c}$ shows no difference between the mean arcs per trial for the baited and unbaited standard-arm floor maze $[F(1,18)=1.28]$ and no change over trial blocks $[F(3,54)=1.29]$.

Proportion of distance traveled. Figure 7 shows that, overall, the baited and unbaited rats distributed their log proportions of distance traveled unequally between arm travel, wall travel, and open travel $[F(2,36)=5.25]$. Although there were no overall differences between groups or trial blocks, there were two significant interactions, involving group $\times$ trial block $[F(3,54)=6.71]$ and group $\times$ travel type $[F(2,36)=14.2]$, and an interaction between travel type and trial block $[F(6,108)=11.5]$.

The rats on the baited floor RAM showed a trial-block effect $[F(3,27)=6.79]$ and an interaction of travel type $\times$ trial block $[F(6,54)=8.05]$. Subsequent tests showed that arm travel increased and wall travel decreased over trials $\left[F_{\mathrm{S}}(3,27)=9.35\right.$ and 9.86 , respectively $]$. A confirmation of the differences among travel types $[F(2,18)=15.7]$ was based on arm travel greater than wall travel and open travel $[F \mathrm{~s}(1,9)=23.3$ and 11.2 , respectively $]$.
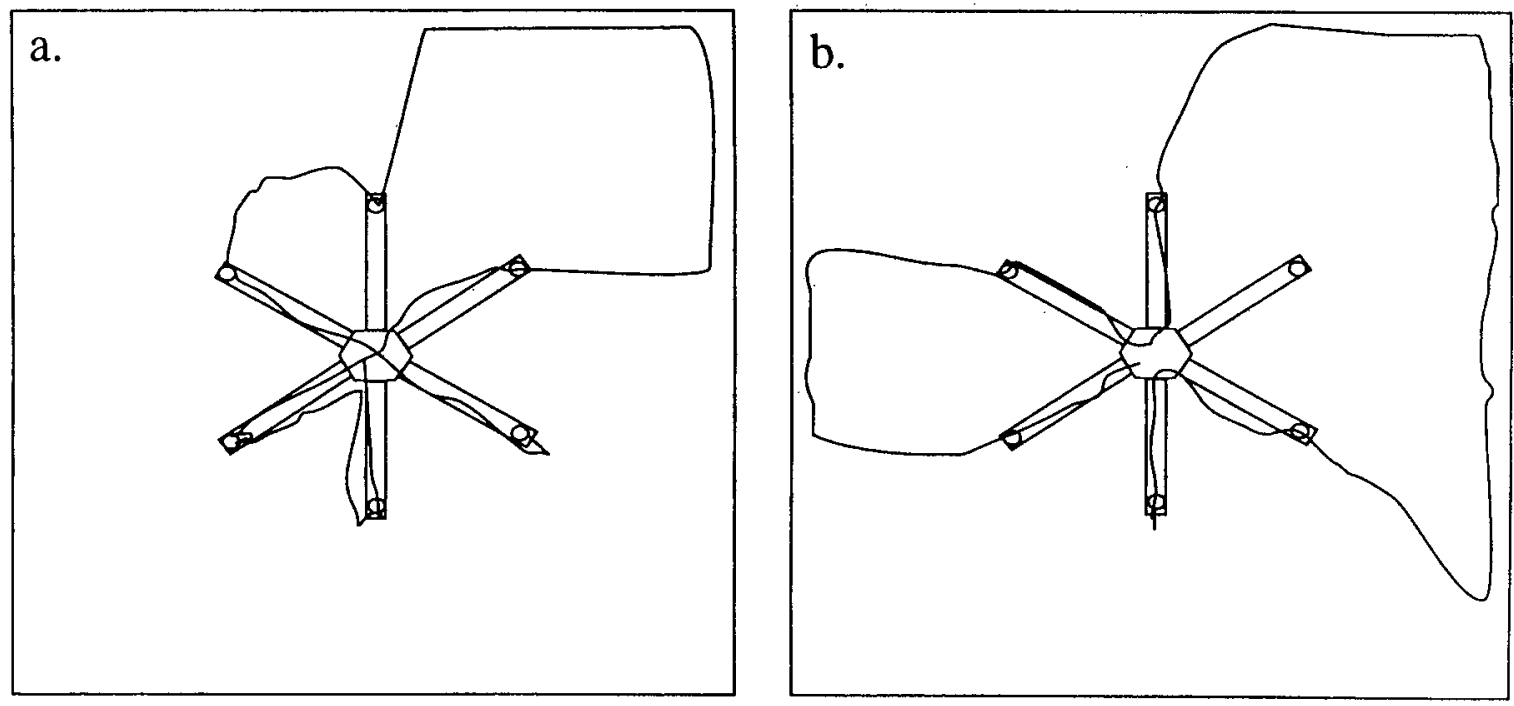

Figure 6. Modal route of the rats in Experiment 2 on (a) the baited standard-arm floor RAM and (b) the unbaited standardarm floor RAM. 
a

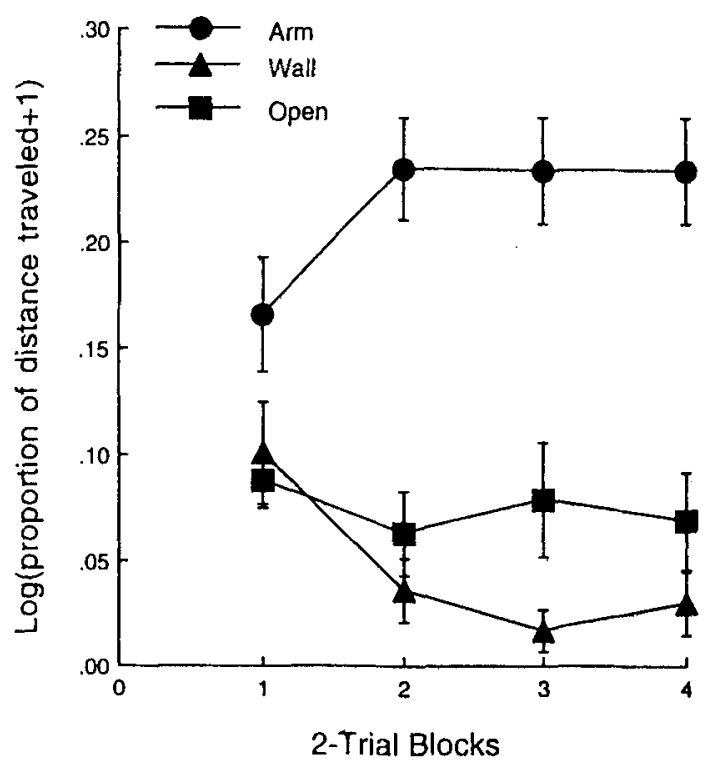

b

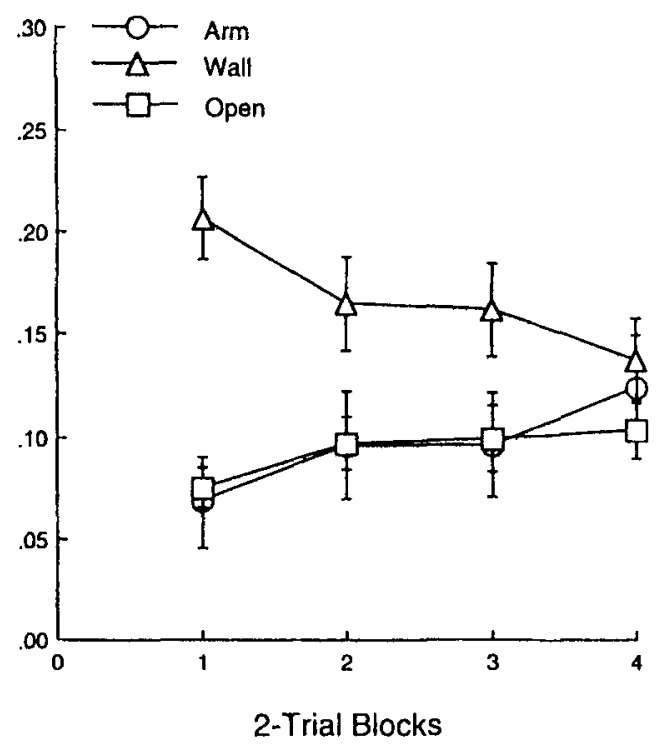

Figure 7. Mean log proportion of distance traveled along arms and walls and in the open by two-trial blocks for the rats in Experiment 2 on (a) a baited standard-arm floor RAM and (b) an unbaited standard-arm floor RAM.

The unbaited floor RAM group showed no overall effect of trial block or travel type, but there was a significant interaction of the two $[F(6,54)=5.14]$. Arm travel increased over trials, whereas wall travel decreased $\left[F_{\mathrm{S}}(3,27)=6.17\right.$ and 9.13 , respectively $]$. Overall, the baited standard-arm rats traveled along arms more and walls less than did the unbaited rats $[F \mathrm{~s}(1,18)=13.6$ and 25.8 , respectively]. It appears that rats shift from walls to arms as preferred trails over trial blocks, but the shift occurs much more rapidly when food is present on the arms.

Effect of odor. Again, we conducted ANOVAs on all dependent variables, comparing the scores of the first 2 rats following a cleaning with the scores of the second 2 rats. As in Experiment 1, there were no significant differences in the performance of the early and late rats on the number of successive visits to adjacent cups, time, or travel pattern (proportion of travel along arms, along walls, or in the open, and number of arcs traveled per trial) for the rats in the baited RAM group. However, for the unbaited RAM condition, the rats tested early in a subgroup visited more novel cups per trial than did the late rats. The rats that ran first visited $79.4 \%$ of the different cups, whereas the rats that ran later visited only $65.8 \%$ of the cups $[F(1,5)=9.77]$.

\section{Discussion}

The key finding of Experiment 2 was that the rats on the unbaited maze increased arm travel over trials even when food was never present on the maze. Not surprisingly, the unbaited rats took longer to search for novel (foodless) cups and initially traveled more along the arena walls, but, by the eighth trial, they clearly had markedly increased arm travel. These results argue that arm travel is a coherent behavior that is controlled primarily by the floor maze arms and not by the reinforcement effects of food.

A second finding on the unbaited maze was the clear tradeoff over trials between wall travel and arm travel. It was not a case of the rat simply spending more time away from the walls over trials. In fact, the amount of open travel did not change across trials. The decrease in wall travel was accompanied only by an increase in arm travel, indicating that wall travel and arm travel have a unique relation. Finally, it was interesting that the only effect of odor appeared to emerge in the unbaited group, in which the rats tested following cleaning of the maze visited more novel cups per trial than did the rats tested later. It may be that social odors in an environment without food are more distracting and/or aversive to hungry rats.

\section{EXPERIMENT 3}

In all conditions of Experiments 1 and 2, the rats increasingly traveled along arms over trials, a pattern of behavior compatible with a locomotor tactic of trail following. Also, in both experiments, arm and wall travel had a complementary relationship in terms of amount of expression. As wall travel decreased, arm travel compensatorially increased. This relationship suggested that both arm travel and wall travel may be related to the foraging tactic of trail following.

Perhaps the biggest surprise in Experiments 1 and 2 was the failure of the rats to minimize the distance of their foraging routes (cf. Stephens \& Krebs, 1986). They 
Table 3

Mean Performance Measures and Standard Errors Averaged by Two-Trial Blocks for Experiment 3

\begin{tabular}{|c|c|c|c|c|c|c|}
\hline & Block 1 & Block 2 & Block 3 & Block 4 & Block 5 & Overall \\
\hline Maze & $M S E$ & $M S E$ & $M S E$ & $M S E$ & $M S E$ & $M S E$ \\
\hline \multicolumn{7}{|c|}{ (a) Mean Number of Novel Cups Visited Out of a Maximum of Six Visits } \\
\hline No arms & 2.90 .5 & 3.80 .3 & 4.40 .3 & 4.60 .3 & 4.60 .2 & 4.10 .2 \\
\hline Circle & 4.90 .3 & 5.10 .3 & 5.10 .3 & 5.60 .1 & 5.90 .1 & 5.30 .1 \\
\hline \multicolumn{7}{|c|}{ (b) Mean Time in Seconds to Complete a Trial } \\
\hline No arms & 44749 & 17234 & 12419 & $72 \quad 12$ & 6311 & 17620 \\
\hline Circle & 628 & 503 & $45 \quad 15$ & 439 & 215 & 446 \\
\hline \multicolumn{7}{|c|}{ (c) Mean Proportion of Successive Visits to an Adjacent Cup } \\
\hline No arms & .46 .07 & .46 .06 & .42 .04 & .58 .06 & .52 .05 & .49 .04 \\
\hline Circle & .67 .04 & .73 .02 & .69 .05 & .76 .04 & .78 .04 & .73 .02 \\
\hline \multicolumn{7}{|c|}{ (d) Mean Number of Arcs } \\
\hline No arms & $0.8 \quad 0.2$ & 1.30 .5 & 1.10 .3 & 1.80 .3 & 1.70 .4 & $\begin{array}{ll}1.3 & 0.2\end{array}$ \\
\hline Circle & 2.90 .2 & $\begin{array}{lll}3.3 & 0.4 \\
\end{array}$ & $\begin{array}{lll}3.5 & 0.3 \\
\end{array}$ & 4.00 .4 & 4.30 .4 & $\begin{array}{ll}3.6 & 0.3 \\
\end{array}$ \\
\hline
\end{tabular}

showed effective foraging in choosing nearly all cups without repeating, but they did not show maximal efficiency in minimizing the length of their search routes. One purpose of Experiment 3 was to determine whether rats might show a distance-minimizing tactic if maze arms did not compete with a minimum-distance route. A second purpose was to explore further the possibility that wall travel and arm travel are alternative forms of trail following, as suggested by the results for the unbaited standard-arm group in Experiment 2.

In the first phase of Experiment 3, the rats were exposed to a floor RAM with all arms removed, leaving only the basic configuration of a center platform surrounded by six food cups. This was termed the no-arms phase. If the presence of maze arms interfered with the expression of a distance-minimizing tactic, we would expect that rats in the absence of any arms would move directly between the food cups. On the other hand, to the extent that trail following is a dominant tactic and thigmotactic search is an expression of it, we could expect wall travel to dominate in the absence of the maze arms.

In the second phase of Experiment 3 (using the same rats), maze arms were placed only between the food cups, creating a continuous circle maze connecting all food cups but without any connections to the center. This was termed the circle-maze phase. If trail following is a dominant tactic and if rats are controlled by some combination of arms as better trails than walls and some tendency to distance minimize, then we would expect the rats to show a large number of arcs between food cups and a minimal distance traveled in visiting novel cups. On the other hand, if walls are better trails than arms in the absence of arms radiating to food from the center starting platform, we would expect little change in the second phase. As in Experiment 1 , the rats were always free to show the alternative tactics of central-place search and random and inefficient search.

\section{Method}

Sixteen naive, adult female rats were obtained, housed, and maintained as in Experiment 1. The center of the maze and cups were placed in the same locations in the experimental room as they were in Experiment 1 , with an arena size of $3.6 \times 3.2 \mathrm{~m}$. In the initial no-arm condition, no arms were placed on the floor. In the subsequent circle-maze condition, arms were placed only between adjacent cups. Each rat was tested for 10 trials in each condition. The procedures and analyses were the same as in Experiment 1, except that, in the no-arms condition, travel along arms was scored when the rat traveled in the locations counted as arm travel in the standard-arm condition of Experiments 1 and 2.

\section{Results}

We divided our analyses into measures concerned primarily with cup visits and measures concerned with patterns of locomotion.

\section{Cup Visits}

Novel cup visits. The rats visited novel food cups at a level significantly above chance in both conditions by the end of testing (Table 3a). In the no-arms condition, the number of novel cups visited in a maximum of six cup visits was not significantly above chance over all trials $[t(7)<1]$ but did increase significantly over trials $[F(4,28)=7.46]$ and was significantly above our estimate of chance during the last trial block $[t(7)=2.80]$. In the circle-maze condition, the number of different cups visited in the first six cup visits was significantly above chance over all trials $[t(7)=11.8]$ and also increased significantly over trial blocks $[F(4,28)=3.30]$.

Time. Table $3 \mathrm{~b}$ shows the time to complete trials over blocks. The rats became significantly faster over trial blocks in both the no-arms condition and the circle-maze condition $[F \mathrm{~s}(4,28)=45.7$ and 4.29 , respectively].

\section{Locomotion Pattern}

Figure 8 shows a modal route for each condition. Modal routes were constructed as in Experiment 1 on the 


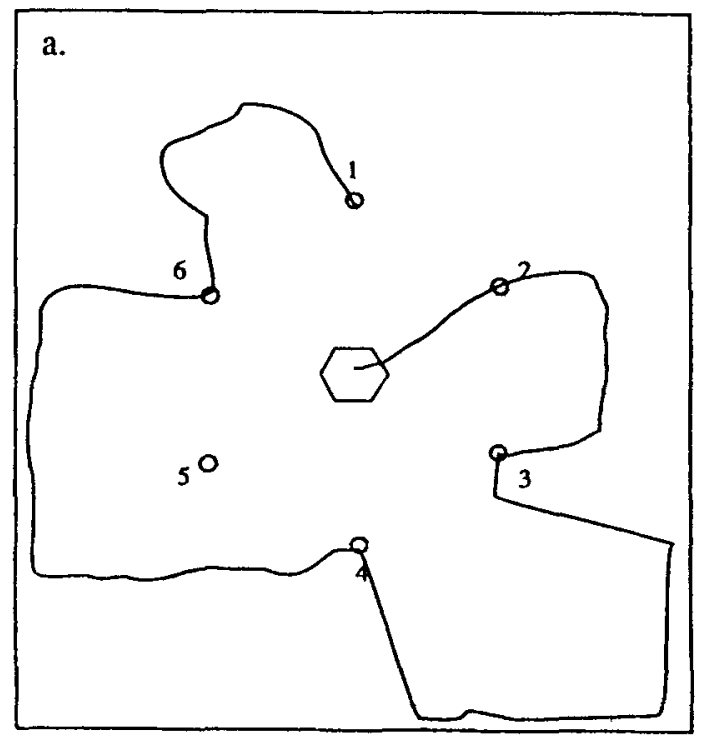

b.

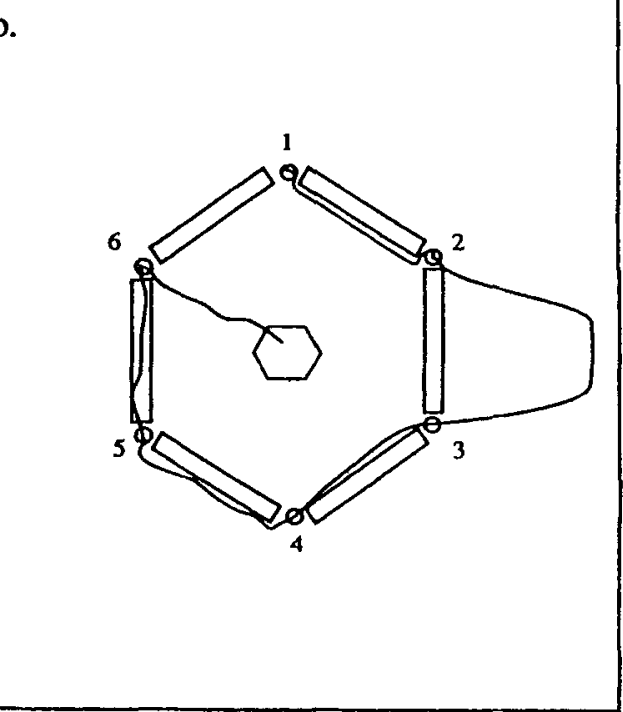

Figure 8. Modal route of the rats in Experiment 3 on (a) the no-arms maze and (b) the circle maze.

basis of the average data from the last four trials. It is clear that the rats did not distance minimize in the no-arms phase. Instead, they showed a "flower petal" route, looping out to the wall between food cup visits (Figure 8a). However, when the circle maze was instituted, the rats rapidly showed stable circling of the maze arms while checking all the food cups (Figure $8 \mathrm{~b}$ ). Neither phase showed much evidence of central-place search or random or inefficient search.

Adjacent cup visits. As Table $3 \mathrm{c}$ shows, the rats tested in both the no-arms condition and the circle-maze condition tended to choose adjacent cups. The proportion of successive adjacent visits for the no-arm rats was $49 \%$, and the proportion for circle-maze rats was $73 \%$, as compared with $38 \%$ for the standard floor RAM rats in Experiment 1 . The average proportion of successive visits to an adjacent cup showed an insignificant increase over trials for the no-arm rats $[F(4,28)=2.56]$, whereas, for the circle-maze rats, successive visits to an adjacent cup began at $67 \%$ and continued with little change over trial blocks $[F(4,28)=1.69]$.

Number of arcs. The number of arcs traveled per trial indicates that the rats did not distance minimize in the no-arms phase, but they did during the circle-maze phase (Table 3d). The average number of arcs traveled in the noarms phase over the last trial block was considerably lower than the 5 arcs that would be traveled by an ideal distance minimizer $[t(7)=7.85]$. The number of arcs traveled in a typical route of a rat on the circle maze over the last two blocks of trials was greater than in the case of the noarms condition and did not differ from the ideal of 5 arcs in the final trial block $[t(7)=1.67]$.

Proportion of distance traveled. As Figure 9a shows, the proportion of travel along arms, along walls, and in the open differed significantly for the no-arms phase
$[F(2,21)=5.44]$. The rats traveled along arena walls and in the open significantly more than they traveled directly between the center platform and a cup $\left[F_{\mathrm{S}}(1,14)=4.97\right.$ and 9.36, respectively]. The proportion of travel along walls and in the open did not differ $[F(1,14)<1]$. Over trial blocks, the proportion of wall travel declined significantly $[F(4,28)=6.94]$, as the proportions of open travel and travel directly between the center and a cup increased significantly $\left[F_{\mathrm{s}}(4,28)=4.97\right.$ and 4.33 , respectively]. However, the predominant pattern was still to move toward the wall between food cups rather than move in an arc directly between them.

In contrast, in the circle-maze phase, the rats traveled along the circle arms more than they traveled along the walls of the room or in the open areas (Figure $9 b$ ). The proportion of travel along arms, along walls, and in the open differed significantly $[F(2,21)=64.8]$. The rats traveled along arms significantly more than they traveled along walls $[F(1,14)=78.6]$ and significantly more than they traveled in the open $[F(1,14)=80.9]$. The proportion of travel along walls and in the open did not differ $[F(1,14)<1]$. Over trial blocks, the proportion of arm travel increased significantly $[F(4,28)=4.55]$, and the proportion of wall travel decreased significantly $[F(4,28)=$ $4.44]$. The proportion of open travel did not change over trial blocks $[F(4,28)<1]$.

Effect of odor. There were no significant differences in performance of the early and late rats on measures of accuracy, time to complete a trial, and travel pattern for either the no-arms phase or the circle-maze phase.

\section{Discussion}

The rats during both the no-arms phase and the circlemaze phase visited more novel cups per trial than was expected by our conservative estimate of chance. Their 
a

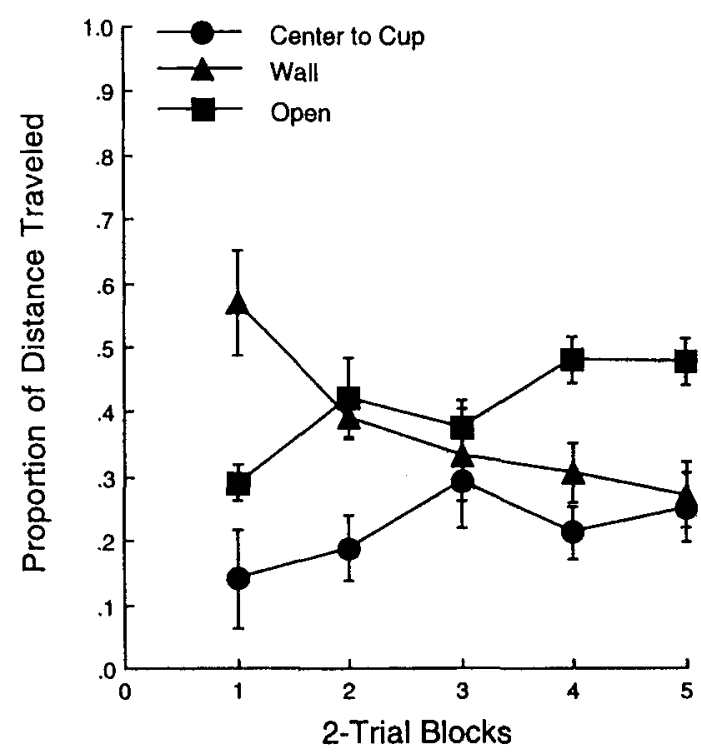

b

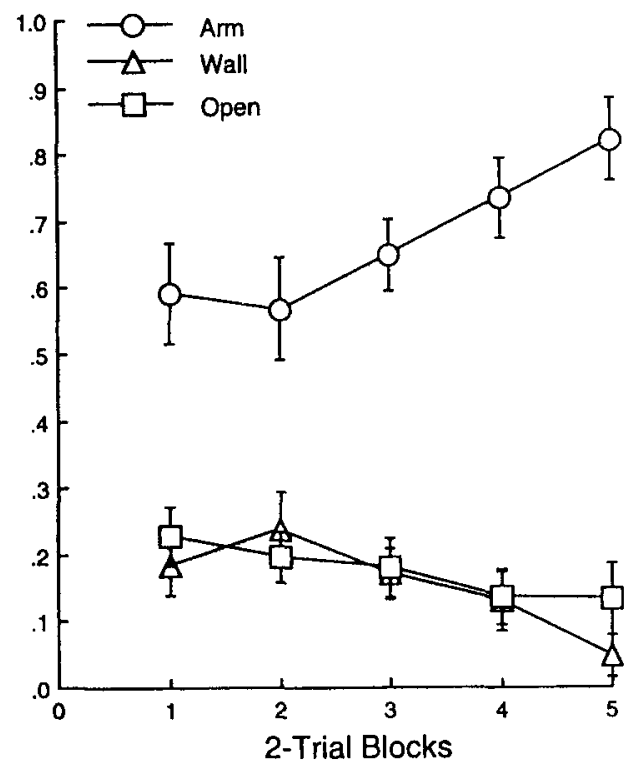

Figure 9. Mean proportion of distance traveled along arms and walls and in the open by two-trial blocks for the rats in Experiment 3 on (a) the no-arms maze and (b) the circle maze.

locomotor patterns, though, differed with the circumstances. The rats in the no-arms phase most frequently visited the food cups by walking along the wall between cups. In contrast, the rats in the circle maze phase overwhelmingly traveled along the maze arms between food cups. In both cases, the choice of adjacent cups was unusually high. Note that, on the circle maze, it was again clear that the rats did not arm travel because they were physically restricted to the maze arms. The rats traveled on the floor next to the maze arms on $89 \%$ of the cups they visited traveling along an arm, locomoting both inside and outside the "circle" formed by the maze arms connecting the cups.

In short, as in Experiments 1 and 2, the most consistent account of locomotor pattern was that the rats employed a trail-following tactic. In Phase 1 , the rats predominantly wall traveled, whereas in Phase 2, they almost exclusively traveled along the maze arms. Distance minimizing occurred in the circle maze, where it was compatible with trail following. It did not occur when the only trail available was along the wall of the arena. In neither phase did the rats show a central-place foraging pattern by traveling back and forth between the central platform and the food cups (although it would have been a shorter route than wall travel), nor did they randomly search the arena.

While the data strongly supported the importance of a trail-following tactic, the exact pattern of trail-following appeared influenced to a degree by efficiency considerations. Over trials, in the no-arms phase, the rats decreased the distance traveled by less frequently traveling all the way to the wall before turning toward the next cup. Furthermore, their performance in the circle maze phase reached a higher asymptote of distance minimizing than was shown on the circle-and-spoke maze in Experiment 1. Please note, though, that these increases in efficiency occurred within the framework of trail following. The rats went directly from cup to cup only when they were supported by a trail connecting the cups and there were no choice points with competing trails.

\section{EXPERIMENT 4}

The results of Experiment 3 also supported the importance of a trail-following tactic that is expressed in both arm travel and wall travel. The results of the circlemaze condition also showed that the rats distance minimized, provided the maze arms led only from one food cup to the next and nowhere else, so there were no competing trails. In other words, distance minimizing appears to be a secondary tactic to trail following. It occurs in purest form only when maze arms trace a distanceminimizing route (see also Roche \& Timberlake, 1998). However, it remains possible that distance minimizing is a primary locomotor tactic that we have not engaged because the relative or absolute difference between trail following and distance minimizing was too small.

The main purpose of Experiment 4 was to explore the possibility that a primary distance-minimizing tactic will emerge when the cost of trail following, relative to distance minimizing, is increased. In the arms-to-walls condition of Experiment 4, maze arms were placed only at right angles between each food cup and the arena wall. In the armsaround-walls condition, additional maze arms were added along the walls. In both conditions, if the rats closely fol- 
$\mathbf{a}$

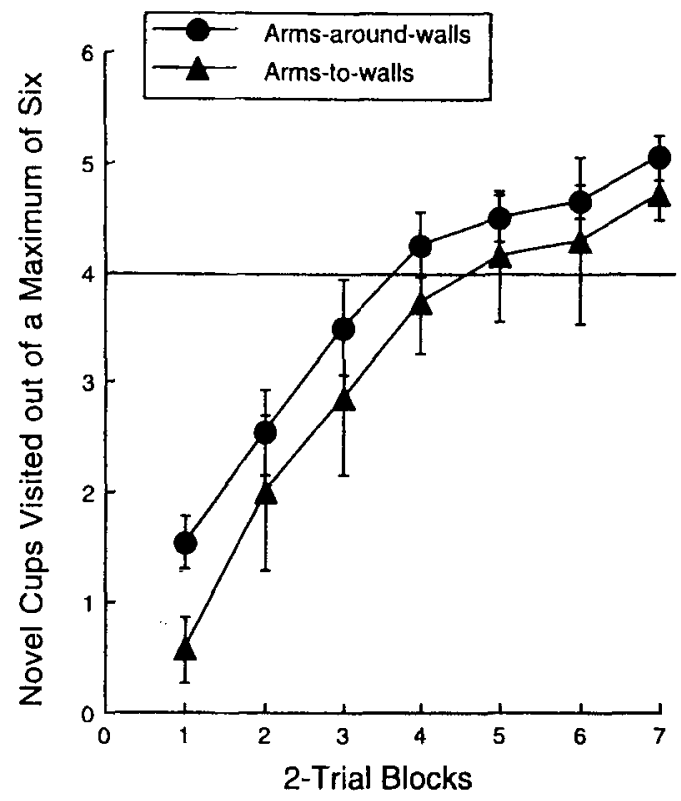

b

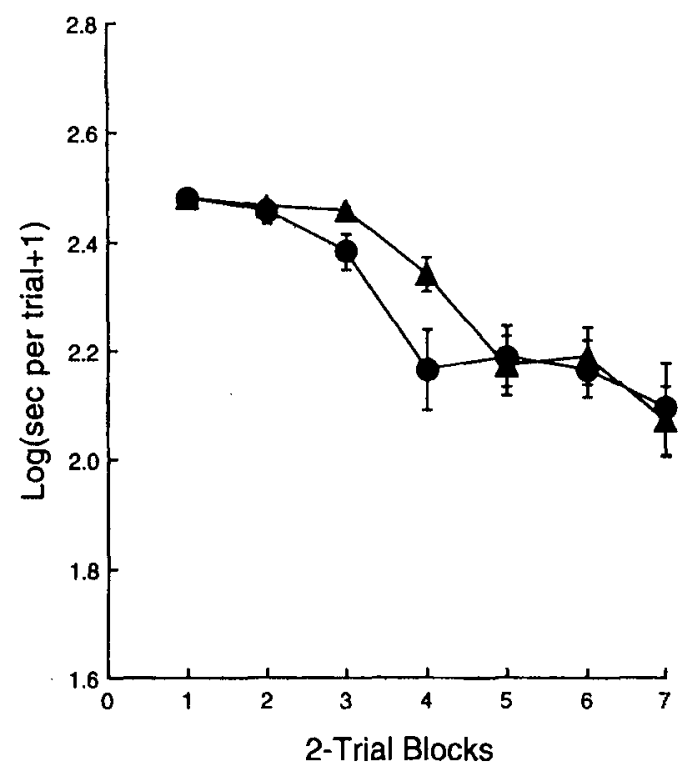

Figure 10. Accuracy and time measures of cup visits on arms-to-walls and arms-around-walls mazes by two-trial blocks in Experiment 4. (a) Mean number of novel cup visits in a maximum of six visits. (b) Mean log time to visit a maximum of six cups. (The solid line in panel a shows the number of novel cup visits predicted by chance, per Figure 2.)

lowed the maze arms and the arena walls between food cups, they would travel three times as far as a rat traveling directly between the cups (an absolute difference of $11 \mathrm{~m}$ ).

A second question we addressed was the potential role of the borders of the maze arms in disrupting or facilitating movement. In the arms-to-walls condition, the borders of the maze arms went all the way to the wall, thereby interrupting any wall trail rather than providing a continuous trail around the walls if the rat approached the wall on top of the maze arm or on the side of the arm opposite the next novel cup. In contrast, in the arms-around-walls condition, the borders stopped $13 \mathrm{~cm}$ short of the wall at a point of intersection with the borders of other arm sections placed along the walls. Together the arms provided an uninterrupted route along the wall and into the maze cups. If the discontinuity in the wall route provided by the borders in the arms-to-wall condition is important, we would expect more wall travel in the continuous arms-around-walls condition. It is important to note again that the borders projected $1.9 \mathrm{~cm}$ above the surface of the maze arm and in no way physically limited the rats from leaving or returning to the arms of the maze. Any effect of a continuous border in controlling behavior was likely mediated by visual and/ or tactual contact.

\section{Method}

\section{Subjects}

Eighteen naive rats were randomly assigned to each of two experimental conditions, 8 in the arms-to-walls group and 10 in the arms-around-walls group. They were obtained, housed, and main- tained as in Experiment 1. One of the rats in the arms-to-walls condition failed to leave the center platform on two of the first three trials and was dropped from the study.

\section{Apparatus}

Experimental trials were conducted in a $3.6 \times 3.6 \mathrm{~m}$ arena. The four sides of the arena were constructed of $91.4-\mathrm{cm}$-high plywood walls painted gray. The arms-to-walls apparatus maintained the same relative positions of the center of the maze and the six food cups as for the radial mazes in Experiment 1. Each of the six maze arms was placed between a food cup and the wall of the experimental arena. For the arms-around-walls condition, arms were added that extended all the way around the perimeter of the arena. In this condition, there was no border at the junction between the arm and the wall, so a continuous trail existed around the arena and into the food cups.

\section{Procedure}

The procedures were the same as in Experiment 1 except as noted. When coding route distance, we recorded travel along a maze arm whenever a rat locomoted along one of the arms placed perpendicular to an arena wall between the wall and a food cup. Travel along a wall was recorded whenever a rat traveled along the base of the wall (in the arms-to-walls condition) or along an arm located beside the wall (in the arms-around-walls condition). Open travel was recorded whenever the rat traveled neither along an arm nor along a wall. The rats in both conditions were tested for 14 trials, and each trial lasted a maximum of 5 min.

\section{Results}

We divided our analyses into measures primarily concerning cup visits and measures concerned with patterns of locomotion. 
a.

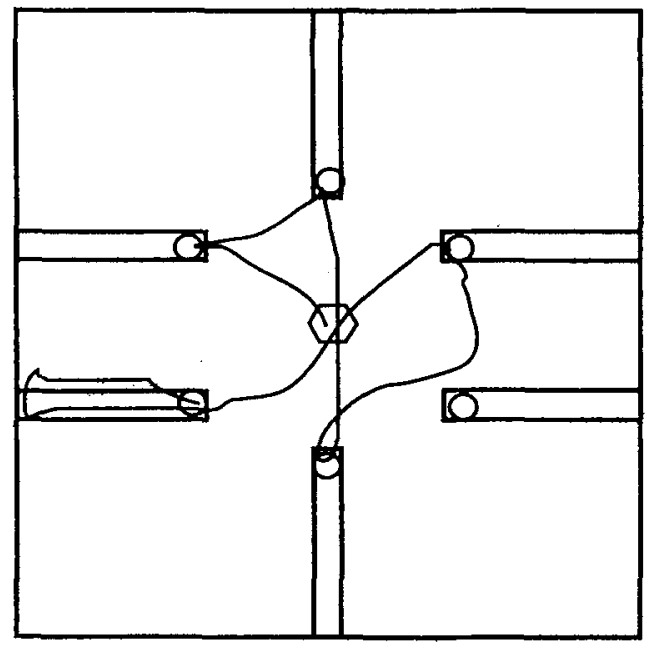

b.

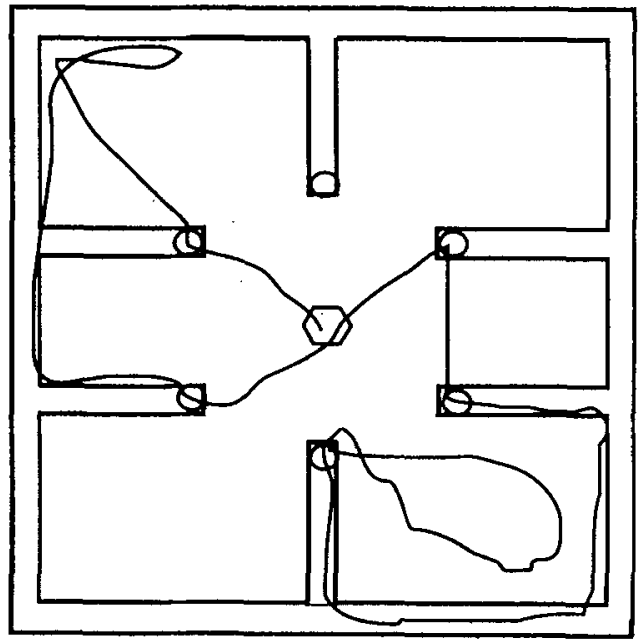

Figure 11. Modal route of the rats in Experiment 4 on (a) the arms-to-walls maze and (b) the arms-around-walls maze.

\section{Cup Visits}

Novel cup visits. Figure 10a shows that rats in both the arms-to-walls condition and the arms-around-walls condition did not differ over blocks of trials, in visiting novel cups. However, both groups increased the number of novel cups visited in a maximum of six visits over trial blocks $[F(6,90)=29.0$, and $F(6,54)=18.1$, respectively $]$. Averaged over the last two blocks of trials, the number of novel cups visited in a maximum of six cup visits was above chance for both the arms-to-walls group and arms-aroundwalls group $[t(6)=2.20$, and $t(9)=7.61$, respectively].

Time. The arms-to-walls and arms-around-walls rats decreased their average log time to complete a trial over trial blocks $[F(6,36)=28.9$, and $F(6,54)=25.1$, respectively] (Figure 10b). The arms-to-walls rats completed trials as rapidly as the arms-around-walls rats $[F(1,15)<1]$.

\section{Locomotion Pattern}

Figure 11 shows a modal route for each condition, constructed from the average data of the last four trials, as outlined in Experiment 1. Figure 1 1a indicates that the rats in the arms-to-walls condition came closer to distance minimizing than the rats in any condition except the circlemaze condition, and they also came closer to centralplace foraging and random search. However, as statistical tests on individual measures showed, the variance was high. Figure $1 \mathrm{lb}$ shows that the rats in the arms-aroundwalls condition were most inclined to follow arms, although not always all the way around the arena.

Adjacent cup visits and number of arcs. The proportion of successive visits to adjacent cups did not differ between the arms-to-walls and arms-around-walls groups $[F(1,15)=2.94]$ (Table $4 a)$. It was initially low and increased significantly over trial blocks for both groups $[F(6,36)=4.70$, and $F(6,54)=7.96$, respectively]. Similarly, the number of arcs was low and did not differ significantly between the arms-to-walls and armsaround-walls groups $[F(1,15)=1.80]$ (Table $4 b$ ). The average number of arcs did increase significantly over trial blocks for both groups $[F(6,36)=3.71$, and $F(6,54)=$

Table 4

Mean Performance Measures and Standard Errors Averaged by Two-Trial Blocks for Experiment 4

\begin{tabular}{|c|c|c|c|c|c|c|c|c|c|c|c|c|c|}
\hline \multirow[b]{2}{*}{ Maze } & \multicolumn{2}{|c|}{ Block 1} & \multicolumn{2}{|c|}{ Block 2} & Block 3 & Block 4 & Block 5 & \multicolumn{2}{|c|}{ Block 6} & \multicolumn{2}{|c|}{ Block 7} & \multicolumn{2}{|c|}{ Overall } \\
\hline & $M$ & $S E$ & $M$ & $S E$ & $M S E$ & $M \quad S E$ & $M S E$ & $M$ & $S E$ & M & $S E$ & $M$ & $S E$ \\
\hline \multicolumn{14}{|c|}{ (a) Mean Proportion of Successive Visits to an Adjacent Cup } \\
\hline Arms to walls & .10 & .07 & .27 & .09 & $.27 \quad .07$ & $.31 \quad .06$ & $.36 \quad .10$ & .42 & .10 & .45 & .06 & .36 & .06 \\
\hline Arms around walls & .20 & .06 & .30 & .08 & $.31 \quad .06$ & $.54 \quad .04$ & $.48 \quad .05$ & .50 & .04 & .59 & .05 & .42 & .03 \\
\hline \multicolumn{14}{|c|}{ (b) Mean Number of Arcs } \\
\hline Arms to $\mathrm{w}$ & & & 0.29 & 0.15 & 0.360 .18 & 0.430 .17 & 0.570 .25 & 0.71 & 0.15 & 1.00 & 0.24 & 0.48 & 0.09 \\
\hline Artms around walls & 0.05 & 0.05 & 0.4 & 0.16 & 0.550 .20 & 0.850 .21 & 1.050 .27 & 1.05 & 0.26 & 1.25 & 0.30 & 0.74 & 0.15 \\
\hline \multicolumn{14}{|c|}{ (c) Mean Number of Cup Visits From the Center } \\
\hline Arm & 0.360 & 0.24 & 1.00 & 0.36 & 2.000 .56 & 3.000 .39 & 2.860 .61 & 2. & & & 0 . & 2.15 & 0.33 \\
\hline Arms around walls & 0.700 & 0.20 & 0.90 & 0.22 & 1.600 .30 & 1.950 .23 & 2.100 .24 & 1.90 & 0.31 & 1.90 & 0.16 & 1.58 & 0.14 \\
\hline
\end{tabular}


a

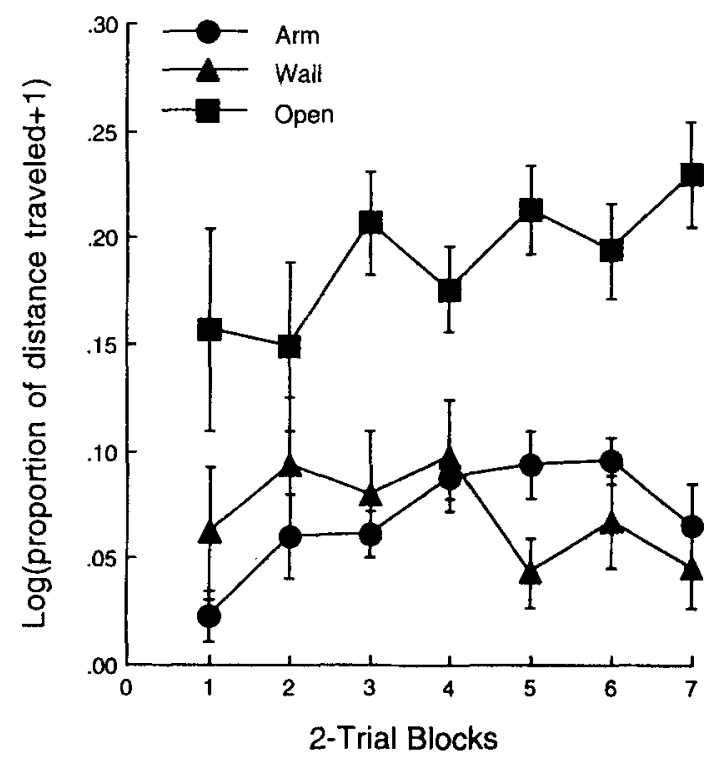

b

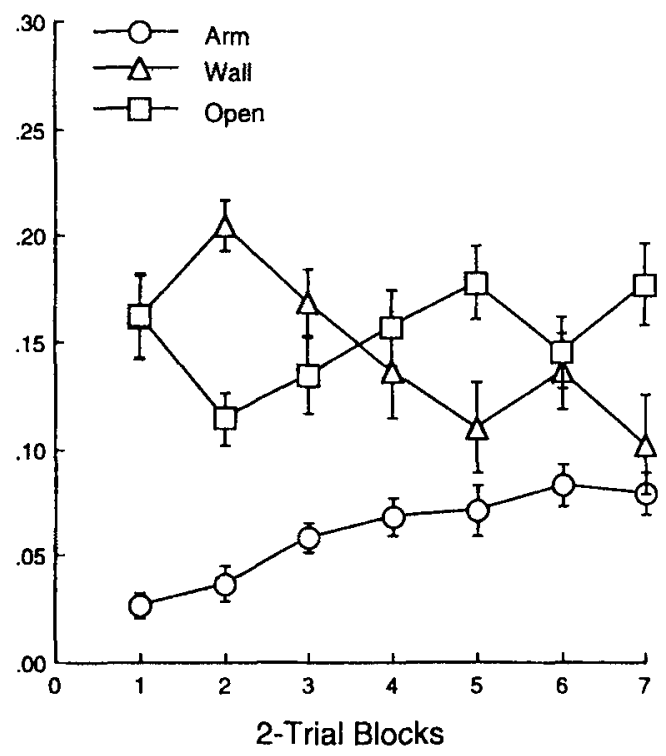

Figure 12. Mean log proportion of distance traveled along arms and walls and in the open by two-trial blocks for the rats in Experiment 4 on (a) the arms-to-walls maze and (b) the arms-around-walls maze.

5.64 , respectively], but the number of arcs traveled over the last two trial blocks in the arms-to-walls and armsaround-walls groups was still significantly lower than that predicted for a distance minimizer $[t(6)=9.14$, and $t(9)=18.5$, respectively $]$.

Proportion of travel. Figures $12 \mathrm{a}$ and $12 \mathrm{~b}$ show an overall effect of trial block $[F(6,90)=3.07]$, travel type $[F(2,30)=25.1]$, and group $[F(1,15)=9.97]$. There were two significant interactions: group $\times$ travel type $[F(2,30)=$ $7.92]$ and trial block $\times$ travel type $[F(12,180)=4.67]$. Not surprisingly, the arms-to-walls group showed less wall travel than did the arms-around-walls group $[F(1,15)=$ 13.8]. The arms-to-walls group alone (Figure 12a) shows a travel-type effect $[F(2,12)=23.2]$ that is based on open travel exceeding travel along perpendicular maze arms and wall travel $[F \mathrm{~s}(1,6)=42.6$ and 19.0 , respectively $]$.

The arms-around-walls group (Figure 12b) showed an effect of travel type $[F(2,18)=12.9]$ and a travel $\times$ trial block interaction $[F(12,108)=5.83]$. Over trial blocks, the proportion of travel along the perpendicular maze arms increased $[F(6,54)=7.25]$, whereas the proportion of travel along walls decreased $[F(6,54)=6.98]$. Over all trial blocks, the proportion of travel along the perpendicular arms was smaller than the proportions of wall travel and open travel $\left[F_{\mathrm{s}}(1,9)=25.1\right.$ and 46.9 , respectively $]$. The high proportion of travel in the open in the arms-towalls group, relative to the arms-around-walls group, appeared related to a greater tendency for the former to travel from the central platform to the food cups and back-in essence, a central-place search route.

To compare the tendency toward central-place search for both groups, we counted the number of cup visits that the rats made directly from the center of the maze
(Table 4c). The number of cup visits from the central platform increased significantly over trial blocks for both the arms-to-walls rats (from 0.36 to 3.14 visits) $[F(6,36)=$ 12.9 ] and the arms-around-walls rats ( 0.70 to 1.90 visits) $[F(6,54)=6.89]$. Although the arms-to-walls group visited cups significantly more often from the center of the maze than did the arms-around-walls group during the last two trial blocks $[F(1,15)=7.9]$, both groups visited significantly fewer cups from the center of the maze than the six that would be expected of an ideal central-place forager $[t(6)=8.6$, and $t(9)=22.8$, respectively] .

Effect of odor trails. To determine whether odors left on the maze and floor by the rats that ran early in a testing group had an effect on the foraging behavior of the rats tested later in the group, we conducted ANOVAs on all dependent variables, comparing the early rats with the late rats. There were no significant differences in performance of the early and late rats on accuracy, time, or travel pattern for any of the three groups.

\section{Discussion}

The rats predominantly traveled along the armsaround-walls maze even though the distance traveled was up to three times that of a distance-minimizing route and twice that of a central-place route. This appears to be further evidence of the strength of trail following as a primary foraging tactic that motivates efficient performance on a RAM. In partial contrast, though, the rats on the arms-to-walls maze traveled more in the open in a route that bore some resemblance to central-place search. This finding suggests that the presence of arms with borders extending all the way to the wall disrupted both wall travel and arm travel and may have promoted open travel 
by providing a form of low landmark to orient to. A similar conclusion can be reached by noting that there was less wall travel in the arms-to-walls maze than in the noarms condition of Experiment 2.

Finally, the present data support the contention that rats prefer to follow continuous (uninterrupted) trails (Timberlake, 1983a). This preference may be due to a dependence of locomotion on visual and tactual contact with vertical edges (see Munn, 1950; Roche \& Timberlake, 1998; Timberlake, Leffel, \& Hoffman, 1999).

\section{GENERAL DISCUSSION}

Regardless of the configuration of our floor RAM, the rats in the present experiments eventually achieved a degree of food discovery effectiveness similar to that of rats on a standard elevated RAM. Whether the arms were arranged in the standard radial pattern, in a circle or a circle-and-spoke pattern, around the edge of the arena, or were missing altogether, with repeated trials, the rats avoided revisits to food cups while discovering nearly all available food pellets. However, this common effectiveness in discovering food without repeats was not matched by the efficiency of the locomotor routes or the speed with which the rats visited the food cups. The only similarities in locomotor pattern across the different configurations were the following: (1) During the first several trials, the rats tended to extensively explore most of the arena, differentially but not exclusively attending to the walls and the arms; and (2) by no later than the third twotrial block, the rats in each group traveled extensively along maze arms regardless of how the arms were configured or whether the arms were baited. If there were no arms, the rats traveled along the arena walls to food.

The major theoretical point of the present research was to explore what locomotor foraging tactic might underlie the effective use of short-term spatial memory in gathering food in maze-like environments, especially in the case of the common elevated RAM. On the basis of our data and those of Roche and Timberlake (1998), the tactic that appeared most important was trail following represented in the form of traveling along arms and the arena wall. The tactics of distance minimizing, centralplace search, and random search were not influential or, at best, were subservient to the tactic of trail following. For example, the rats increased distance minimizing when maze arms traced a distance-minimizing route without offering an alternative.

When the arms did not uniquely trace a distanceminimizing or central-place search route, the rats primarily traveled along arms or (in the absence of all arms) along the walls of the arena. When the arms dead-ended against the arena wall interrupting continuous locomotion, the rats appeared to fall back on a combination of centralplace, distance-minimizing, and random locomotor search. But when provided an uninterrupted arm route, even when it was three times longer than the distance-minimizing route, the rats arm traveled increasingly over trials.

\section{Borders}

Although low borders $(3.8-\mathrm{cm}$ pieces of hard fiberboard extending $1.9 \mathrm{~cm}$ above the top of the $1.9-\mathrm{cm}$-thick arm) are common on the arms of elevated mazes, their presence on our floor maze arms inevitably raises the question of how directly they influenced the tendency to arm travel. It is clear that the presence of borders intersecting the wall in the arms-to-walls condition of Experiment 3 interfered with movement along the walls, relative to the arms-around-walls condition of Experiment 3 and to the no-arms condition of Experiment 2. However, our data also show clearly that the borders did not physically confine the rats to the arms.

In their initial exploration of the arena, the rats found the arm borders of little consequence. They repeatedly moved on, off, and across the maze arms without hesitation, and they entered food cups while standing both on and off the arms. Furthermore, even when the more experienced rats predominantly arm traveled, they were not confined to the maze arm. On average, the rats were as likely to travel alongside the arm as to walk on top of it. On the last two trials of the standard floor RAM condition, $30 \%$ of visits to food cups that included arm travel occurred alongside rather than on top of the arm. The rats on the unbaited RAM traveled next to the arms on $58 \%$ of cup visits that included arm travel. At asymptote, the circle-and-spoke maze rats visited cups by traveling on the floor next to the maze arms on $79 \%$ of their cup visits that involved arm travel.

Finally, there is every indication that arm travel occurs even when it is considerably less efficient than alternative strategies. The rats tested here increased their arm traveling over trials even when more direct travel between food cups would have decreased the total distance traveled by one half to one third, even when the arms did not connect to the center platform and even when there was no food present. Similarly, Roche and Timberlake (1998) showed that rats predominantly arm traveled when arms did not lead to food or led to food in a zig-zag path. In both cases, the rats eventually showed a tendency to procure food more efficiently by leaving the arms, but their initial behavior was markedly determined by the arms. Even in the presence of obvious visual cues (beacons) that were capable of guiding locomotion in the absence of maze arms, if maze arms also were present, the rats traveled along them rather than distance minimizing on the basis of the beacons.

In short, the predominance of arm and wall travel suggests that trail-following mechanisms are powerful determinants of search behavior in rats given exposure to stimuli bearing even rough resemblance to trails. The present data also support the hypothesis that trail following is an important contributor to foraging in arenas and mazes. 
Rats apparently follow maze arms initially because of attractive stimulus qualities of the arms and borders, rather than because of distance minimizing, central-place search, random search, reinforcement of approach, or physical constraint. They likely travel along walls at least partly because of similar attractive stimulus qualities.

\section{Generalizing the Results}

The apparent pervasiveness of trail-following behavior revealed in our data should not be a surprise given the predominance of trail making and trail following by rats in less constrained settings (Calhoun, 1962; Telle, 1966). Not only do rat colonies rapidly establish trails interconnecting burrows and food sources, but, once trails are established, rats are rarely found off them (Telle, 1966). Trail following appears to be a critical behavior in the life history of a rat, presumably because, on average, it promotes the efficient location of shelter, conspecifics, and food.

However, given the importance of trail following in social colonies, the absence in our data of a strong odor effect on locomotor search might seem surprising (see Galef \& Buckley, 1996; though see also Olton \& Samuelson, 1976). The only evidence of an effect appeared in the unbaited RAM condition. The rats tested following cleaning of the unbaited maze visited slightly but significantly more novel cups per trial than the rats tested later $(79.4 \%$ vs. $65.8 \%)$ when odor cues likely had accumulated on the maze and floor. It is possible that hungry rats avoid visiting areas that may be without food even in the absence of any experience with food in the environment (Morrison \& Ludvigson, 1970).

Finally, the present research provided further support for an animal-centered ecological view of learning like the behavior systems approach (Timberlake, 1983b, 1984, 1990, 1994, 1997, 1999; Timberlake \& Lucas, 1989). An animal-centered view argues that animals efficiently perform food-reinforced laboratory tasks, such as the elevated RAM, most readily when the task maps well onto components of natural foraging behavior. In this view, popular apparatus, stimuli, and procedures have been "tuned" by experimenters to fit the underlying motivational and perceptual-motor organization of animals (Timberlake, 1983b, 1990, 1994).

The present results support the hypothesis that the typical elevated RAM has been tuned to enlist speciestypical "operating characteristics" of Norway rats that are related to trail following and effective search. Although our data do not prove that rats on an elevated maze are using trail-following tactics and win-shift rules, the compelling qualities of maze arms on the floor in a free-choice environment combined with similarities in levels of novel cup and adjacent arm choice and the speed of acquisition curves all argue for similar mechanisms. One potential difference between elevated and floor RAM performance is that male and female rats showed no difference on our standard-arm floor RAM (Hoffman, Timberlake, \& Gont, 1995), whereas some experimenters have found males slightly better than females on a complex elevated maze (Seymoure, Dou, \& Juraska, 1996). Further work is necessary to produce comparable data, but these data suggest the possibility that performance on our floor RAM depends less on visuospatial memory than does performance on an elevated maze.

While the tuning of an apparatus to a particular species places potential limits on the generality of the results, it also provides the opportunity to specifically explore the particular contribution of the animal's sensorimotor and motivational organization to both laboratory and "realworld" behavior (see Balsam \& Silver, 1994; Tinbergen, 1951). For example, Timberlake (1983a) altered physical and reward characteristics of a typical straight-alley experiment to clarify what the rat's sensorimotor repertoire contributed to straight-alley running. Asymptotic running times were more related to the increased familiarity of the rats with an uninterrupted and relatively lengthy trail with borders than to the presence of food at the end.

Using a similar strategy, in the present experiments, we altered the RAM apparatus and procedures to learn more about how the locomotor tactics of rats relate to maze arms. The behavior of rats appeared highly related to trail following as expressed by traveling along maze arms and along the walls when maze arms were absent. That the behavior of laboratory rats should show such mechanisms should not be a surprise given the considerable data that laboratory and wild rats show similar behavior patterns, differing primarily in threshold of expression (cf. Timberlake, 1990).

\section{REFERENCES}

BALSAM, P. D., \& Silver, R. (1994). Behavioral change as a result of experience: Toward principles of learning and development. In J. A. Hogan \& J. J. Bolhuis (Eds.), Causal mechanisms of behavioral development (pp. 327-357). Cambridge: Cambridge University Press. Barnett, S. A. (1975). The rat. Chicago: Chicago University Press. BättiG, K., \& SChlatter, J. (1979). Effects of sex and strain on exploratory locomotion and development of nonreinforced maze patrolling. Animal Learning \& Behavior, 7, 99-105.

Beatty, W. W., \& Shavalia, D. A. (1980). Rat spatial memory: Resistance to retroactive interference at long retention intervals. Animal Learning \& Behavior, 8, 550-552.

CalHoun, J. B. (1962). The ecology and sociology of the Norway rat (Publication No. 1008). Bethesda, MD: U.S. Department of Health, Education and Welfare.

GALEF, B. G., JR., \& BUCKLEY, L. L. (1996). Use of foraging trails by Norway rats. Animal Behaviour, 51, 765-771.

Hoffman. C. M., Timberlake, W., \& Gont, R. (1995). [Performance of male vs. female rats on a radial arm maze on the floor]. Unpublished data.

KreBs, J. R., \& MCCleery, R. H. (1984). Optimization in behavioral ecology. In J. R. Krebs \& N. B. Davies (Eds.), Behavioural ecology (2nd ed., pp. 91-121). Sunderland, MA: Sinauer.

LimA, S. L., \& Dil.L, L. M. (1990). Behavioral decisions made under the risk of predation: A review and prospectus. Canadian Journal of Zoology, 68, 619-640. 
Morrison, R. R., \& Ludvigson, H. W. (1970). Discrimination by rats of conspecific odors of reward and nonreward. Science, 167, 904905 .

MuNN, N. L. (1950). Handbook of psychological research on the rat: An introduction to animal psychology. Boston: Houghton Mifflin.

OLTON, D. S. (1982). Staying and shifting: Their effect on discrimination learning. In M. L. Commons, R. J. Herrnstein, \& H. Rachlin (Eds.), Quantitative analyses of behavior: Vol.2. Matching and maximizing accounts (pp. 205-226). Cambridge, MA: Ballinger.

OLTON, D. S. (1983). Memory functions and the hippocampus. In W. Seifert (Ed.), Neurobiology of the hippocampus (pp. 335-373). New York: Academic Press.

Olton, D.S., \& SAMUELSON, R. J. (1976). Remembrance of places passed: Spatial memory in rats. Journal of Experimental Psychology: Animal Behavior Processes, 2, 97-116.

Phelps, M. T., \& Roberts, W. A. (1989). Central-place foraging by Rattus norvegicus on a radial maze. Journal of Comparative Psychology, 103, 326-338.

Roche, J. P., \& Timberlake, W. (1998). The influence of artificial paths and landmarks on the foraging behavior of Norway rats (Rattus norvegicus). Animal Learning \& Behavior, 26, 76-84.

Seymoure, P., Dou, H., \& JuRaska, J. M. (1996). Sex differences in radial maze performance: Influence of rearing environment and room cues. Psychobiology, 24, 33-37.

StePhens, D. W., \& KrebS, J. R. (1986). Foraging theory. Princeton, $\mathrm{NJ}$ : Princeton University Press.

Suzuki, S., Augerinos, G., \& Black, A. H. (1980). Stimulus control of spatial behavior on the eight-arm maze in rats. Learning \& Motivation, 11, 1-18.

TELLE, H. J. (1966). Beitrag zur Kenntnis der Verhaltensweise von Ratten, vergleichend dargestellt bei, Rattus norvegicus und Rattus rattus [Contribution to knowledge of the behavior of rats, a comparative study of Rattus norvegicus and Rattus rattus]. Zeitschrift fur Angewandte Zoologie, 48, 97-129.

Timberlake, W. (1983a). Appetitive structure and straight alley running. In R. L. Mellgren (Ed.), Animal cognition and behavior (pp. 165221). New York: North-Holland.
TimberlaKe, W. (1983b). The functional organization of appetitive behavior: Behavior systems and learning. In M. D. Zeiler \& P. Harzem (Eds.), Advances in the analysis of behavior, Vol. 3: Biological factors in learning (pp. 177-221). Chichester, England: Wiley.

Timberlake, W. (1984). An ecological approach to learning. Learning \& Motivation, 15, 321-333.

Timberlake. W. (1990). Natural learning in laboratory paradigms. In D. A. Dewsbury (Ed.), Contemporary issues in comparative psychology (pp. 31-54). Sunderland, MA: Sinauer.

TimberLAKE, W. (1994). Behavior systems, associationism, and Pavlovian conditioning. Psychonomic Bulletin \& Review, 1, 405-420.

TimberLAKE, W. (1997). An animal-centered, causal-system approach to the understanding and control of behavior. Applied Animal Behaviour Science, 53, 107-129.

TimberlaKe, W. (1999). Biological behaviorism. In W. O'Donohue \& R. Kitchener (Eds.), Handbook of behaviorism (pp. 243-284). San Diego: Academic Press.

Timberlake, W., Leffel, J., \& Hoffman, C. M. (1999). Stimulus control and function of arm and wall travel by rats on a radial arm floor maze. Animal Learning \& Behavior, 27, 445-460.

Timberlake, W., \& LuCAs, G. A. (1989). Behavior systems and learning: From misbehavior to general principles. In S. B. Klein \& R. R. Mowrer (Eds.), Contemporary learning theories: Instrumental learning and the impact of biological constraints on learning (pp. 237. 275). Hillsdale, NJ: Erlbaum.

Timberlake, W., \& White, W. (1990). Winning isn't everything: Rats need only food deprivation and not food reward to efficiently traverse a RAM. Learning \& Motivation, 21, 153-163.

TinBergen, N. (1951). The study of instinct. New York: Oxford University Press, Clarendon Press.

USter, H. J., BätTIG, K., \& NÄGELI, H. H. (1976). Effects of maze geometry and experience on exploratory behavior in the rat. Animal Learning \& Behavior, 4, 84-88.

(Manuscript received August 19, 1998; revision accepted for publication June 16, 1999.) 